\title{
Students' Perceptions of the Impact of Online Education on Health during COVID-19: A Survey Study
}

Krishna Prasad K. ${ }^{1}$, Vinayachandra ${ }^{2}$, Geetha Poornima K. ${ }^{3}$, \& Rajeshwari M. ${ }^{4}$

${ }^{1}$ Associate Professor, College of Computer \& Information Sciences, Srinivas University, Mangalore, Karnataka, India

Orcid ID: 0000-0001-5282-9038; E-mail: krishnaprasadkcci@srinivasuniversity.edu.in ${ }^{2}$ Research Scholar, College of Computer \& Information Sciences, Srinivas University, Mangalore, Karnataka, India and Assistant Professor, Dept of Computer Science, St Philomena College, Puttur, Karnataka, India

Orcid ID: 0000-0002-9374-4871; E-mail: veeciashu@ gmail.com

${ }^{3}$ Research Scholar, College of Computer \& Information Sciences, Srinivas University, Mangalore, Karnataka, India and Assistant Professor, Dept of Computer Science, St Philomena College,

Puttur, Karnataka, India

Orcid ID: 0000-0001-9095-0349; E-mail: poornima.sanjay@gmail.com

${ }^{4}$ Research Scholar, College of Computer \& Information Sciences, Srinivas University, Mangalore, Karnataka, India and Assistant Professor, Dept of Computer Science, St Philomena College,

Puttur, Karnataka, India

Orcid ID: 0000-0001-9613-4967, E-mail: rajimuraleedhar@gmail.com

Area/Section: Health Sciences.

Type of the Paper: Empirical Research.

Type of Review: Peer Reviewed as per $|\mathrm{C}| \mathrm{O}|\mathrm{P}| \mathrm{E} \mid$ guidance.

Indexed in: OpenAIRE.

DOI: $\underline{\text { http://doi.org/10.5281/zenodo.5149609 }}$

Google Scholar Citation: IJHSP

\section{How to Cite this Paper:}

Krishna Prasad K., Vinayachandra, Geetha Poornima, K., \& Rajeshwari, M. (2021). Students' Perceptions of the Impact of Online Education on Health during COVID-19: A Survey Study. International Journal of Health Sciences and Pharmacy (IJHSP), 5(2), 1-27. DOI: http://doi.org/10.5281/zenodo.5149609.

International Journal of Health Sciences and Pharmacy (IJHSP)

A Refereed International Journal of Srinivas University, India.

Crossref DOI : https://doi.org/10.47992/IJHSP.2581.6411.0071

(C) With Author.

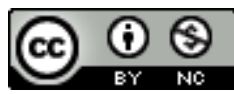

This work is licensed under a Creative Commons Attribution-Non-Commercial 4.0 International License subject to proper citation to the publication source of the work.

Disclaimer: The scholarly papers as reviewed and published by the Srinivas Publications (S.P.), India are the views and opinions of their respective authors and are not the views or opinions of the SP. The SP disclaims of any harm or loss caused due to the published content to any party. 


\title{
Students' Perceptions of the Impact of Online Education on Health during COVID-19: A Survey Study
}

\author{
Krishna Prasad K. ${ }^{1}$, Vinayachandra ${ }^{2}$, Geetha Poornima K. ${ }^{\mathbf{3}}$, \& Rajeshwari M. ${ }^{4}$ \\ ${ }^{1}$ Associate Professor, College of Computer \& Information Sciences, Srinivas University, \\ Mangalore, Karnataka, India \\ Orcid ID: 0000-0001-5282-9038; E-mail: krishnaprasadkcci@ srinivasuniversity.edu.in \\ ${ }^{2}$ Research Scholar, College of Computer \& Information Sciences, Srinivas University, Mangalore, \\ Karnataka, India and Assistant Professor, Dept of Computer Science, St Philomena College, \\ Puttur, Karnataka, India \\ Orcid ID: 0000-0002-9374-4871; E-mail: veeciashu@ gmail.com \\ ${ }^{3}$ Research Scholar, College of Computer \& Information Sciences, Srinivas University, Mangalore, \\ Karnataka, India and Assistant Professor, Dept of Computer Science, St Philomena College, \\ Puttur, Karnataka, India \\ Orcid ID: 0000-0001-9095-0349; E-mail: poornima.sanjay@gmail.com \\ ${ }^{4}$ Research Scholar, College of Computer \& Information Sciences, Srinivas University, Mangalore, \\ Karnataka, India and Assistant Professor, Dept of Computer Science, St Philomena College, \\ Puttur, Karnataka, India \\ Orcid ID: 0000-0001-9613-4967, E-mail: rajimuraleedhar@gmail.com
}

\begin{abstract}
Purpose: This empirical research aims to see whether students in higher educational institutions are satisfied with technology-assisted Online Education during the COVID-19 pandemic and its effect on their physical mental and emotional health. The findings of this study could help policymakers and healthcare professionals develop effective psychological therapies and costefficient recommendations for preventing negative feelings among general people who are solitary at home.
\end{abstract}

Methodology: To demonstrate the demographic and other selected features of the respondents, a descriptive analysis was done. Due to the non-normal distribution of the data, a non-parametric test was employed to investigate the significant correlations between sample characteristics and the level of health problems during the COVID-19 outbreak. The connection between gender, education level, and age group vs the stated level of health problems was evaluated using a One-Way ANOVA test for independence.

Findings/Result: It was found that too much exposure to mobile and laptop screens is currently one of the major disadvantages of online education and leads to a feeling of isolation and fear. It may indicate distress and an increased abnormal or obsessive tendency like picking nails, sucking the thumb, and pulling the hair. Excessive use of gadgets even resulted in mental health problems, stress sensations, anxiety, excitation or thrill, headaches, tiredness of the muscle, eye and ear strains, obesity or overweight, faintness, irregular sleep patterns, mental disturbance, back pain, aching shoulders, neck, and muscles pain, etc. Online education also affected the physical activity levels of students like bad postures, later bedtimes, longer sleep rise discontinuation, and later waking times which has been associated with motionless and lazy lifestyles.

Originality: The study used data collected through an online survey to learn how students are dealing with online education, which has been around for a long time but is still underutilized, and how satisfied they are with it. During June 2021, data was obtained. The online survey form was kept open for a week to allow respondents to reply. The participating population does not have a regional boundary

Paper Type: Empirical research.

Keywords: COVID-19, Health Crisis, Online Education, One-Way ANOVA, Perception. 


\section{INTRODUCTION :}

COVID-19, a new pandemic caused by a novel coronavirus, has almost all sectors, including education. As a result, higher education and its students will be the most affected by the outbreak in 2020 [1]. The majority of students were pleased with the university's actions throughout the lockdown. In reaction to the rising coronavirus outbreak, colleges have been obliged to close their doors and, where the IT infrastructure allowed, transfer classes to online learning to keep learners' engagement and opportunity to learning [2-3]. Schools and teachers did not always have the necessary abilities to switch from face-to-face to online teaching with ease, which could mean that the educational process did not expect the same level of quality. The immediate closure and transition from physical to online sessions have created numerous challenges in the learning and teaching process [4]. The normal flow of learning and teaching has been disrupted. To maintain social distance, more limits and uncertainties have been placed, leading to a shift in learning and education toward digital learning with technical equipment and related abilities [5]. Technology can be a useful tool, but it will never be able to replace face-to-face communication [6]. Online learning allows for virtual communication and involvement while learning. As a result, for the new academic year, the university's management must take effective and efficient efforts to eliminate, as much as possible, these negative difficulties and improve the performance of the online educational process. To reap the greatest benefits from online education, one must be ready and prepared for this emergency phase [7]. Students are worried about their education and are unable to communicate with their professors and peers in person. They had issues with slow internet connections and the gadgets most of which were required for active participation in the online class. Furthermore, economically underprivileged students are more likely to have outdated or limited computing gear, as well as less reliable home internet access, placing them at a disadvantage compared to their more affluent counterparts [8]. Social isolation can lead to stress-related emotions and a decrease in overall happiness [4]. Students were put under pressure by sudden demands for a wide range of talents, as well as contests with more resources [9]. So, while online courses make it easier for students and teachers to get an education [10], they may become more sedentary and develop health problems as a result. Students typically spend a significant amount of time on the internet as part of their online education. This will naturally move their interests away from physical activities like walking, outdoor games, and exercises and toward sedentary entertainment like watching movies and playing video games.

The impact of technology on their mental, physical, and emotional health is maybe the most significant consequence [11]. Students' attitudes about instructional technology had a direct impact on their learning process, and a negative attitude harmed their academic achievement. Numerous studies have discovered detrimental health effects in these settings. The following are a few of these impacts.

Excessive Internet media exposure raises the likelihood of addiction to intoxicants. The study of the impact of technology on a group of 6,515 youngsters and discovered a significant difference in the rate of overweight and obesity among those who spent a lot of time with technology; it is also discovered that a statistically meaningful link between increased computer time and excess weight [12]. Sleep issues, depression, migraines, loss of appetite, and stomach concerns were the most prevalent physical symptoms. As students engage in more and more cyber activity, their self-reflection and concentration levels naturally decline. This puts both physical and mental strain on the body. Long periods of screen time and a lack of outside activities can harm children's vision, thus adequate eye-protection measures should be applied. Online lessons can now be taken from the comfort of one's own home, with no need for peers or teachers as in a traditional classroom. Physical health will be harmed in a variety of ways if there is no physical mobility of the body and incorrect posture is utilized to take online classes for lengthy periods. Physical inactivity can lead to a loss of muscle tone, making it more difficult to manage sports in the future. Exercises and physical activities in the morning and evening, as well as a healthy diet, will help to raise calcium and vitamin D levels in the body. Online lessons, on the other hand, will not allow any child to be exposed to such activities, which could lead to deficits in recent days and years [13]. Long periods spent in the same position by students and professors in online classes can lead to a variety of health problems in higher education. Both students and professors have experienced comparable physical health issues such as back discomfort, neck pain, eye pain, headaches, inability to sleep, anxiousness, and other minor issues [14]. In the context of the current COVID-19 outbreak, public health advice and government initiatives have imposed lockdowns and prohibitions. While the lockdown serves to reduce infection rates, they also have negative consequences by restricting involvement in typical everyday activities, physical activity, travel, and access to numerous types of exercise such as gyms, as well as greater social isolation [15].

Frustration, tension, anger, worry, and melancholy are some of the psychological concerns that might arise

Krishna Prasad K., et al., (2021); www.srinivaspublication.com 
as a result of lockdown, which can negatively affect students' mental health [16]. Online learning has altered daily routines such as outdoor exercise, sleeping time and style, and loneliness, all of which may have an impact on online learners' mental health [17]. Furthermore, several types of research have been conducted to analyze the mental health of students of all ages using a variety of characteristics such as sleeping habits, daily fitness routines, and social support [18]. Epidemics and infection impacts may exacerbate or provoke new stressors; dread of losing loved ones, financial loss, inadequate supplies, boredom, restrictions placed on social activities and movements, due to social isolation have altered everyone's lifestyle [19]. During the pandemic, 1.5 billion learners over the globe were deprived of their fundamental education, which had a significant negative influence on their mental health [20]. The purpose of this survey is to look into the influence of the COVID-19 epidemic on students' education, health, and lifestyle. Because of their health problems, their academic progress also suffered. Mental health disorders can have an impact on selfmotivation, attentiveness, and communication skills, all of which are critical for success in higher education [21].

Because people care for and are concerned about their families, anxiety is always one of the psychological concerns that arise in humans. People are scared of events that occur in such outbursts. Posttraumatic tension disorder and obsessive-compulsive disorder are widespread, debilitating, and costly concerns [22]. Data collected through various study approaches provide information regarding people's attitudes, feelings, and behaviors such as joyous, glad, and sad as a result of the pandemic sickness and events [23]. The current study aims to determine the occurrence and spread of anxiety, emotional status, and protective activities among students, as well as evaluate their correlations with media exposure, using a quick evaluation during the COVID-19 outbreak. As a result of the circumstances in Covid-19, many students are likely to face tension, concern, and anxiety, so it is critical to provide emotional support to students [24]. All of this puts a lot of pressure on students, leading to feelings of burnout as a result of academic stress, whereas emotional development begins in childhood and affects children in a variety of ways, including ego development, emotional development, and social development [25].

This study attempts to determine the influence of online teaching and learning on education and student health during the COVID-19 pandemic. The findings of this study could help policymakers and healthcare professionals develop effective psychological therapies and cost-efficient recommendations for preventing negative feelings among general people who are solitary at home. A global analysis will assist us in developing the best recommendations for policymakers and higher education institutions on how students may be helped in various crises, including economic, social, cultural, political, and institutional crises.

\section{REVIEW OF LITERATURE :}

Previous studies have shown that the more physically active a child is during their developing years, the better their physical and mental health will be for the next three to four decades. Later bedtimes, greater sleep onset latency, and later waking periods have all come from technology advancements. Computer games and other forms of screen time have been linked to a more sedentary lifestyle. Due to the dread of COVID-19, this might lead to cognitive distress, unpleasant emotions, and hostility, as well as poor sleep quality and a feeling of numbness. Teachers and students throughout the world have been affected by these difficulties, which have damaged their emotional, psychological, and social well-being. Early works on online education and its implications on teacher and student health are the topic of the following literature review.

By calculating $\mathrm{p}=0.045$, the author discovered a strong association between the number of hours spent in online classes and health concerns. According to Dangal, \& Maharjan [13], long hours of online classes and sitting in the wrong (occasionally) and same postures caused eye and back problems in Kathmandu University instructors and students. Even the majority of the students complained, with $27 \%$ having anxiety concerns and $13.5 \%$ having sleep issues. Back pain, neck pain, eye pain, and headaches affected several of them, as well as other minor issues.

Because Hamza et al. [19] did not notice greater rates of clinically significant symptoms reported pre-and during COVID-19, and innovative results suggest that the mental health condition on college and university campuses in the context of COVID-19 may not be as severe as specific writers have cautioned. The prevalence rates of clinically severe symptoms, on the other hand, were comparable. During COVID-19, the author noticed a decrease in wellness and an increase in depressive symptoms among students who had no prior mental health issues. Their findings show that rising social maltreatment (especially isolation and loneliness) among such students may explain at least some of their misery. 
Chaturvedi et al. [12] conducted a survey and were successful in determining the impact of the COVID-19 outbreak on student mental health and education. The study determined the stress levels of different age groups of students, as well as appropriate coping mechanisms for dealing with them. They also uncovered the causes of the health problems, such as sleeping patterns, fitness routines, and social isolation, which occurred during the lockdown. These factors may have an impact on the psychological health of students enrolled in online classes. According to a survey of Mt. San Antonio College, online education students conducted by Froman et al. [21] 79.2\% of students were moderate to highly concerned about their mental and physical health. According to the results of the Covid-19 Student Survey, many students are having difficulty balancing their academic workload and studying in an online setting. Economic difficulties and concerns about their mental and physical health exacerbate these problems.

Händel et al. [11] investigated the effects of tension scales, overload, concern, and joy on socio-emotional scores. Students discussed their feelings of loneliness and emotional loneliness as a result of their use of digital devices. They discovered that pupils who were ready for digital learning had less tension, anxieties, emotional loneliness, and joy than those who were not. Those students were found to be more stressed and lonelier.

Online teaching and learning cannot give a face-to-face learning environment in which students or professors can interpret their emotions. It is not recommended for younger children to spend more time in front of a screen watching online lessons because this can lead to mobile device addiction as well as mental and visual difficulties. In fact, in India, underprivileged students are unable to buy the devices required for online education. As a result, their inability to attend such online programs has caused them anxiety, which has a detrimental influence on their mental and physical health. Even pupils will not sit in typical classrooms for long periods. Even students will not sit for long periods as they do in traditional classrooms. As a result, Yadav [26] discovered in his paper a report of students' willingness to return to traditional classes shortly after the pandemic. Hasan and Bao [27] researched psychological suffering and the anxiety of students losing an academic year. Students' perceptions revealed that e-learning and the fear of academic year loss influenced students' mental health. Because of resource inequity and limited internet access, only a few students may participate fully in online classes, and more students may not be able to do so right away. This will harm their emotions, causing students to experience psychological distress.

Zhao et al. [18] discovered that $76 \%$ of students in China were considering home-schooling and that teachers were concerned about the students' enthusiasm, focus, and academic performance. More than 3 hours of screen time and fewer than 2 hours of outdoor physical activity were mentioned by $69 \%$ of parents. $95 \%$ of parents are concerned about their children's vision, as well as emotional and behavioural issues. During the pandemic days, the authors also found higher levels of anxiety than usual.

Chakraborty et al. [28] discovered that a significant percentage of students suffer from various mental issues based on empirical investigations conducted in several countries throughout the world. They are experiencing worry, despair, addiction, and even suicidal thoughts as a result of the pandemic and their careers. They fell behind in online education due to a lack of enthusiasm and unpleasant feelings. They are scared of losing their internet connection when taking online classes; hence they are worried about getting sick. According to their poll, $82.7 \%$ of students believe that online education has led to an increase in the usage of digital technologies. In addition, $74.6 \%$ are concerned about excessive screen use, which creates stress and disrupts students' sleep. On online assessments, $54.2 \%$ of students reported feeling more anxious than on traditional forms of evaluation in offline, face-to-face classroom education.

According to a survey conducted by Son et al. [29], $71 \%$ of students have increased stress, depressing thoughts, and anxiety. During the COVID-19 pandemic, this tension and anxiety were created by their health and that of their loved ones, a lack of communication owing to social isolation, diminished academic activity and performance, and irregular sleeping patterns. They attempted to locate mental health counseling. As a result, students experienced both bad and good consequences on academic, health, and lifestyle outcomes over this period. Kecojevic et al. [30] performed a cross-sectional study to identify the academic and mental health issues that students encounter. The authors discovered that students are suffering from significant levels of depression, which has affected their academic performance and resulted in job losses. Senior students were shown to have higher levels of anxiousness than freshmen. They also discovered that female students are under more stress than their male counterparts and that they are having difficulty obtaining prescriptions plus cleaning supplies. The anxiety of such non-freshmen was detected and heightened by seeking information regarding COVID-19 on social media. 


\section{OBJECTIVES :}

(1) To understand the perception of students on online education

(2) To find challenges of online education on students' health

(3) To find how online education affected students' physical, mental and emotional health

(4) To find out how the behavior of students changes before and during the pandemic

\section{HYPOTHESIS :}

1. $\mathrm{H}_{1}$ : Online education has a significant impact on students' eye health

2. $\mathrm{H}_{2}$ : There was no significant change in the students' habit frequency before or during the COVID19 pandemic.

3. $\mathrm{H}_{3}$ : Students suffered greatly during the lockdown of COVID-19 under stress and anxiety

4. $\mathrm{H}_{4}$ : The students were under academic stress and poor emotional wellness during online training because of the COVID 19 pandemic.

\section{SCOPE OF THE STUDY :}

This empirical research aims to see whether students in higher educational institutions are satisfied with technology-assisted Online Education during the COVID-19 pandemic and its effect on their physical mental and emotional health. The study used data collected through an online survey to learn how students are dealing with online education, which has been around for a long time but is still underutilized, and how satisfied they are with it. During June 2021, data was obtained. The online survey form was kept open for a week to allow respondents to reply. The participating population does not have a regional boundary. However, the majority of the respondents are from the states of Karnataka and Kerala, India. The study aimed to find answers to the following research questions:

- Is online education the right choice for further education in this pandemic situation?

- Is online training affecting the health of students?

- Is online education challenging the health of students?

- Is COVID-19 involved in student behavioral change?

As with the majority of studies, the design of the current study is subject to limitations. They are: the respondents are not restricted by geography, the survey did not target a particular demographic, because of their cultural backgrounds or viewpoints on such phenomena, respondents' opinions may be skewed and respondents were given a very short amount of time to record their opinions.

\section{QUESTIONNAIRE DESIGN AND SURVEY IMPLEMENTATION :}

The questionnaire, titled 'Students Perceptions of the Impact of Online Education on Health During COVID19: A Survey Study', consisted of 38 major and 52 minor questions divided into five categories as follows.

(1) Academic characteristics of students: 4 major questions about their name, gender, academic level and the subject of study, and the devices they used to access online education.

(2) Knowledge statement and source of information: 13 major questions about COVID-19 and it's spread \& containment, and source of information

(3) Effect on physical health: 7 major and 14 minor questions on physical activities, screen time, digital eye stress, vision difficulty, injuries, eating habits, and fitness.

(4) Effect on mental health: 8 major and 15 minor questions on sleep habits and patterns, habit frequency, stress and anxiety experience, and control.

(5) Effect on emotional health: 5 major and 17 minor questions on students' emotions since the outbreak of the COVID-19 pandemic.

(6) Overall Experience: 1 major and 6 minor questions on personal experience of online education.

The online questionnaire was made available to participants through Google Forms, a free Google application that allows users to conduct online surveys. The survey was only open to those who were 18 or older and currently enrolled in a higher education institution for data protection considerations. Students were told that the online survey would take about 15 minutes and that it would be about their experiences with online education and its impact on their physical, mental, and emotional health. A self-designed questionnaire in the English language was developed specifically for the study and distributed via the Internet. The Google Form's URL was distributed via social media platforms such as email and WhatsApp. The participants were given one week time to record their responses. The privacy of participants was safeguarded and all data was 
anonymized. The participants were also informed that their participation in the survey was completely voluntary and anonymous. By completing the survey, the participants gave their informed consent.

\section{SURVEY SAMPLE AND METHODOLOGY :}

Sample: The non-probability sampling technique convenience sampling was used to collect data for the study. The aim of using these methods is to come up with hypotheses and conduct exploratory research on the topic. The sample size needed for this study was calculated using an online service provided by Statistics Kingdom (https://www. statskingdom.com/50_ci_sample_size.html). To achieve the required confidence interval, the sample size is calculated as confidence level: 0.95 (95\%), a margin of error: 0.05 . The standard deviation is based on the proportion is: $\sqrt{ }(p(1-p))=0.50$. Calculates the sample size to get the following confidence interval: $0.5 \pm 0.05 . \alpha=1-0.95=0.050 . \mathrm{Z}_{(1-\alpha / 2)}=\mathrm{Z}_{(1-0.050 / 2)}=\mathrm{Z} 0.975=1.96$. The required sample size is: $\mathrm{n}=\mathrm{Z}^{2}{ }_{0.975} * \mathrm{p}(1-\mathrm{p}) / \mathrm{MOE}^{2}=1.96^{2 *} * .5(1-0.5) / 0.05^{2}=385$, rounded up from: 384.15 . A convenience sampling technique was used to select research subjects and the final study sample consisted of 385 subjects who replied to the questionnaire using Google Forms (https://forms.gle/9nXsedemYV6kYjpA9).

Participants: 385 students from higher education made up the current sample. $85 \%$ are enrolled in undergraduate programs, while $15 \%$ are enrolled in Postgraduate programs. Male students make up 55\% of the group, while female students make up $45 \% .66 \%$ of respondents live in cities, $12 \%$ live in suburbs, and $22 \%$ live in rural areas.

Method: To demonstrate the demographic and other selected features of the respondents, a descriptive analysis was done. Due to the non-normal distribution of the data, a non-parametric test was employed to investigate the significant correlations between sample characteristics and the level of health problems during the COVID-19 outbreak. The connection between gender, education level, and age group vs the stated level of health problems was evaluated using a One-Way ANOVA test for independence. A statistically significant two-tailed $p<.05$ was used. To evaluate the problems and benefits of emergency online classes, a comparative table of student perspectives was analyzed. The study is attempting to determine the changes observed in the students, with a particular focus on health issues.

\section{CHALLENGES OF ONLINE EDUCATION ON STUDENTS' HEALTH :}

Good health has a huge impact on the academic performance of students. The young generation is regarded as the future hope of a country. Health issues due to excessive use of technology are acting as hurdles to the educational advancement of students. The negative impact of the COVID-19 pandemic has brought students into renewed focus [31]. As the schools and colleges observed a complete shut-down there was no other way for the educational institutions other than switching to complete online mode. The physical well-being of an individual is considered as the ability of the body to perform daily tasks with utmost ease and comfort [32]. It has a great impact on mental well-being too.

Students who are pursuing education in online mode face several health issues. Several benefits can be quoted as far as online education is concerned but on the other hand, it has a negative influence on the overall wellbeing of students. The increased screen time has a negative influence on the physical, mental, and emotional well-being of an individual. Students usually spend their leisure time doing physical activities such as playing sports and games, cycling, workouts, etc [13]. These days they are more interested in online activities such as browsing, chatting, watching web series, etc. Because of their inclination towards the deskbound entertainment provided by using technology, there is a considerable decline in their physical activities. As a result, a majority of them are facing one or the other issue related to their physical or mental health. Disorders such as obesity, hypertension, cancer, diabetes, anxiety, cardiovascular problems, pains in muscles and joints, eye-related issues, headache, etc., are found in the majority of students [33-34]. Following are some of the health issues often confronted by students during online learning because of their sedentary nature. Figure-1 presents a variety of challenges for online education on the health of students.

(1) Sleep Disorder: Because of an increase in screen time, irregular schedules, strict rules on submission of assignments, stress, minimum physical activities students experience a change in their sleeping patterns. Due to delayed sleep, students will not be able to maintain their mind and body tuned [35]. Because of insufficient sleep at night, students feel sleepy during day time. Hence, they will not be able to concentrate much on online classes. Inadequate sleep, irregular sleeping schedule, consumption of intoxicants, extensive use of energy drinks, excess use of technology light from devices such as computers, smartphones, tablets, etc [36]. are the main reasons for the sleeping disorder [37]. This will harm the academic performance of the students. Students need to be educated on the importance of adequate sleep. Following a healthy lifestyle will enable 
students to overcome sleep disorders.

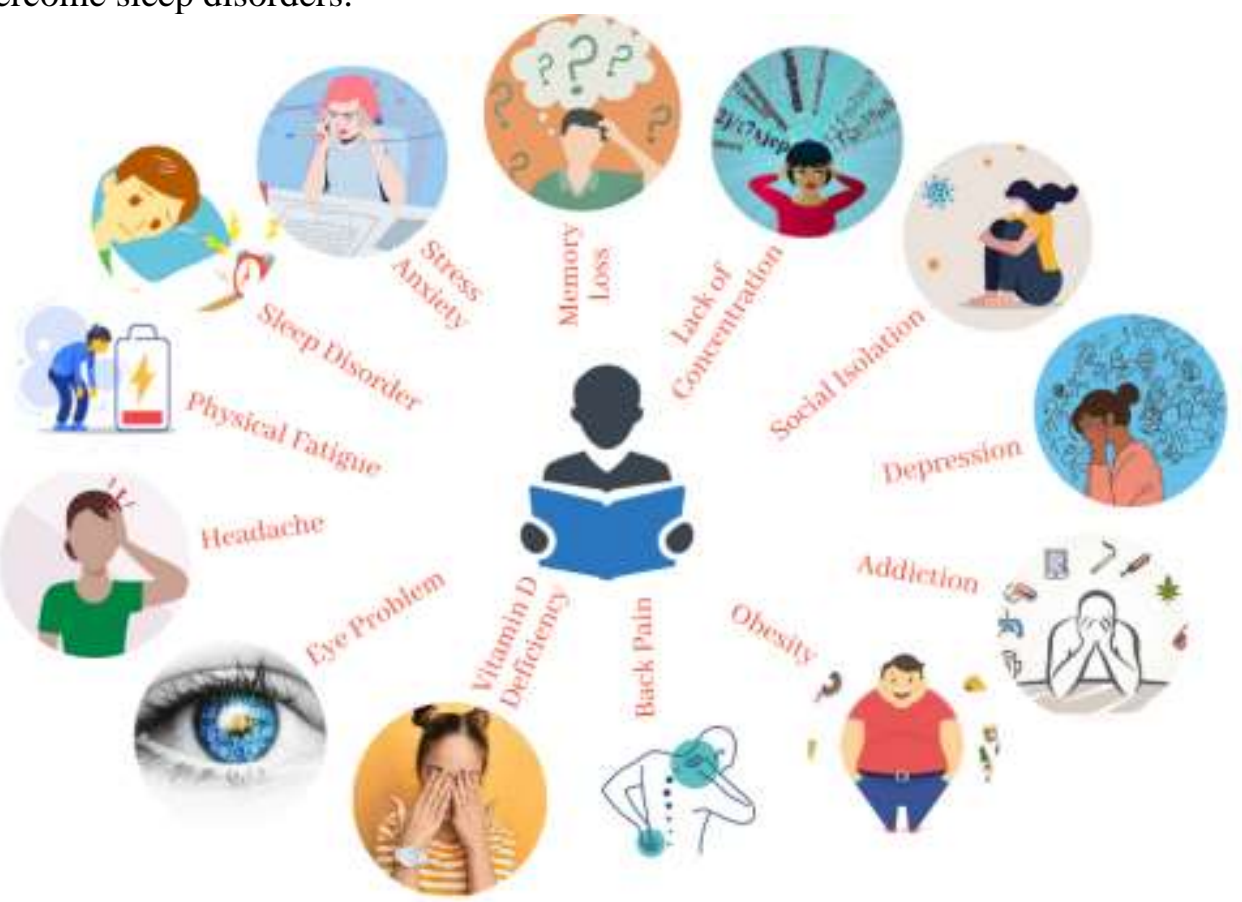

Fig. 1: Challenges of online education on students' health.

(2) Stress and Anxiety: Stress is a state in which a person will not be able to cope with physical and mental pressure. Endless online activities also lead to shortness of temper [38]. It is found that during online learning, because of the mental pressure students feel angry, anxious, afraid, aggressive, irritated, and frustrated [39]. As a result, they may slowly withdraw from their loved ones. Stringent deadlines, fear of the COVID-19, uncertainty of examinations, etc. are some of the reasons for stress during online learning. Stress causes physical health issues such as headache, body pain, sweating, breathing problem, etc [40]. Anxiety is how the brain reacts to stress. It will be different from person to person. Preexisting mental health issues, heredities, etc. will result in anxiety. It is quite normal that students feel stressed and anxious during examinations. Stress and anxiety are experienced by all human beings at different stages. If students feel stressed and anxious every day then it is a disorder. Following a healthy diet, practicing relaxing techniques, regular physical activity can reduce stress and anxiety to a great extent.

(3) Memory Loss: Students often experience memory loss during online learning. Strict deadlines, lengthy classes, uncertainty related to examinations, fear of axiomatizations, interpersonal conflicts may cause too much stress among the students. Stress, depression, and anxiety have a huge impact on learning ability and memory. There is a huge amount of online content in the form of web pages, blogs, videos, and social media posts are available for use [38]. This will increase the cognitive load. When the brain starts processing massive information available it results in excess stress. Also finding the right information becomes a herculean task. When people are provided with many options, there is a possibility that they may choose a bad one. Moving from one type of content to other, scrolling through the digital content creates pressure on the brain and students may feel mentally exhausted [40]. When learning is not systematic, they will not be able to retain it. If they follow the scientific method of learning by choosing the best suitable type of content based on their cognitive ability, they will be able to hold the information for a longer period.

(4) Lack of Concentration: During online classes, students may get easily be distracted by the abundantly available online content. The desire of learning more things can lead the students to browse more and more. This increases their online activities. There is a possibility that with increased screen time, they may tend to lose their focus. In conventional classrooms when students go out of focus, there will be a teacher to bring them back but during online learning, there will not be anyone to warn them. Learning from home requires much conducive atmosphere at home and the surroundings. External distractions such as smells, sounds, sights, people, medical emergencies such as taking care of their sick parents or siblings, lack of sleep, lengthy digital content on the learning material provided, irritation in eyes, headache, caused by increased online activities [35] can contribute more to their lack of concentration. Self-discipline, self-motivation, following a healthy diet, regular sleep patterns, and physical activities can help them overcome a lack of concentration. (5) Social Isolation Colleges are regarded as places of socialization. Students interact with peers, collaborate 
with other students to solve problems, express their feelings with their friends and interact with their teachers [41]. In conventional classrooms, there is more scope for interaction and collaborative activities. Students can voice their opinions [42]. Most companies hire people with good interpersonal and communication skills. Such skills cannot be acquired during online learning as there is limited scope for interaction. Students often feel lonely, isolated, uninterested, and dispirited because of their limited social interaction. Sometimes students feel isolated even they are surrounded by their family members as the interaction among their peers is lacking. Social isolation can increase negativity and, in turn, can cause other physical and mental health issues [43]. Limited interaction with peers can increase preexisting depression, anxiety, and pressure. As a result of increased isolation students may start worrying more about their family members and changes in their friendships. Social isolation cannot be ignored as it becomes the main cause of other health issues such as depression, emotional eating, physical inactivity, etc [44]. It may create a feeling of lack of self-esteem among students. Creating a friendly and positive environment at home and interacting with peers using technology can reduce social isolation to a large extent.

(6) Depression and Suicidal Syndrome: Depression is a mental health disorder that is mainly related to the mood of an individual. An individual who suffers from it experiences different emotions such as extreme sadness, worthlessness, lack of interest in different enjoyable activities [38]. Studies show that this disorder also affects sleeping patterns and appetite. The situations such as stress associated with online classes, deadlines on assignments, death of dear ones, fear of COVID-19, loss of socio-economic balance due to the cost cutdown measures, issues in the family, cancel or postponement of examinations, etc. contribute more to depression. Social isolation experienced due to the sudden closure of schools and colleges has a greater impact on the mental health of students. Utmost depression may also lead to suicidal thoughts or even suicidal attempts. The overwhelming surge of emotions such as helplessness makes one attempt suicide. Feelings of social isolation and extreme depression start bombarding the students and as a result, they begin to develop hatred about themselves and feel like attempting/committing suicide [45]. Talking to friends, being involved in some activities, regular counseling by experts can help students overcome depression and suicidal thoughts. (7) Addiction: When students are unable to cope with the stress and anxiety during online learning, they may get addicted to intoxicants. It gives temporary relief from their physical pain and mental stress but affects the academic performance of the students. As a result of addiction, students lose focus in their studies. Addiction also makes the students experience mood swings. If by any means the confidence level of students is boosted, the possibility of addiction can be reduced. They are to be physically, morally, spiritually, emotionally, and psychologically strengthened to overcome addiction [45].

(8) Obesity: Obesity is a gradual process developed because of following poor and unhealthy diet patterns. It is also called a lifestyle disorder. People who tend to be obese consume more food than the required quantity. It occurs because of eating a large quantity of food, high-calorie food, consuming sugary drinks, and a lonely eating disorder [46]. This will lead to an increase in their body weight [47]. If the body mass index (BMI) of an individual is more than 30, the person is considered obese. Obesity will give rise to other serious health issues such as type 2 diabetes, cardiovascular disorders, hypertension, excess of cholesterol, respiratory problems, difficulty in doing regular work, breakdown of bones, pain in joints and other parts of the body, sleep disorders, and many more [44]. The sedentary nature of online learning catalyzes the eating habits of students. Physical inactivity boosts body weight and as a result, they tend to be obese. Following a balanced diet, practicing regular physical activities can avoid problems associated with obesity [48].

(9) Back Pain: It is no more a secret that during online learning students are required to sit in front of their desktop, laptop, or use their smartphone for a longer period. Attending online classes on their beds, sofas and other furniture often leads to back pain of varying intensities. Sitting in the wrong posture for a long period causes a bend in the spine and slumped backbone, stiffness in the back which will eventually lead to back pain [26]. Adjusting the body to optimal posture, self-awareness about the posture, self-correction of posture, changing the posture frequently, use of ergonomic furniture, some quick upper-body stretching, etc. can help students to overcome back pain to a large extent. Sitting on a comfortable chair at a 90-degree angle with shoulders relaxed with adequate support to the back and arms, feet in a flat position on the floor can avoid back pain to a great degree [28].

(10) Deficiency of Vitamin D and Calcium: In addition to lack of adequate amount of physical activity, sitting inside the house during lockdown causes minimal exposure to sunlight. As a result, students face the deficiency of vitamin D. Deficiency of vitamin D will cause pain in muscles, fatigue, and sometimes depression. The abundance of vitamin D is most essential as it helps the body to utilize Calcium. So, people who suffer from deficiency of vitamin D also have issues related to low-calcium contents. Calcium deficiency 
can cause cataracts, teeth problems, and bone-related issues. Adequate exposure to sunlight, consuming vitamin D-rich food such as fish, egg, milk, yogurt, cheese, etc. can help to increase vitamin D [13]. Physicians suggest students perform some outdoor physical activities so that they get adequate exposure to sunlight to avoid health issues related to deficiency of vitamin D.

(11) Eye Problems: As the students are not accustomed to using the screen for a longer time, they feel strain in their eyes while learning online. Students also face deterioration of their eyesight. Poor adjustment of the screen, improper viewing angle, inadequate lighting in the study room are some reasons for eye strain [49]. The problem in the eyes caused due to the prolonged use of digital devices is referred to as digital eye syndrome (DES). Minor issues related to DES are most common in students who are learning in online mode. The reasons for this include inadequate lighting, glare on the screen, bad seating posture, etc. and the symptoms are strain in eyes, blurred vision, double vision, watering of eyes, dry eyes, and many more. Sometimes it may cause pain in the shoulders and neck. Fortunately, the symptoms of DES are temporary. They will be declined when the screen-time is reduced. During online learning it is not possible to reduce the screen time instead of this, experts suggest that the students must take a short break of few seconds every 30 minutes.

(12) Headache: There is a strong connection between headaches and online learning. Increased screen time during online classes has also resulted in a headache. Headache is also caused due to excess stress during online learning, following incorrect sleeping patterns, improper diet. In addition to this glare on the screen, inadequate light, fluorescent-colored lights, harmful radiation emitted by the digital display devices and improper posture become other causes for headaches [50]. Studies reveal that during online learning, students blink less than the required times. This results in dry eye and ultimately causes headache. As a result of a headache, students feel it difficult to concentrate on their online learning activities. Headache also causes nausea and fatigue. Taking the printouts of digital learning material, use of devices that have larger display areas, adjusting the brightness of the display adequately, drinking enough water, and taking a short break every 30 minutes can reduce headaches to a great extent.

(13) Physical Fatigue: It is a new phenomenon that is observed due to the excess of online activities. Sitting glued to the computer for a long time makes students feel fatigued. Online learning puts extra pressure on them due to which they feel exhausted early. Eyes, shoulders, neck, finger, and arms are used extensively during online learning. They become dominant regions of fatigue. This fatigue is not just physical strain instead it causes anxiety and stress as well. Strained, sore, or burning eyes, feeling restless, headache, the decline in concentration, increased sensitivity to light and sound, exhibiting snappy behavior, paining neck and shoulders that are experienced by students during online learning are referred to as 'digital fatigue. Taking short breaks during online classes, following a healthy diet, using ergonomic furniture when attending online classes, getting more than six hours of sleep per day, and involving in physical activities instead of sitting glued to the screen after online classes can help the student to overcome digital fatigue to a large extent [5152].

\section{ANALYSIS AND INTERPRETATION :}

The personal profiles of the responders are shown in Table-1. Total respondents 385. Male students make up $45 \%$ of the 385 subjects that responded, while female students make up 55\%. Undergraduate students accounted for $85 \%$ of the responses, while postgraduate students accounted for $15 \%$. Urban institutions are attended by $66 \%$ of respondents, suburban institutions by $22 \%$, and rural colleges by $12 \%$. A whopping $92 \%$ of respondents use their smartphones to participate in online education discussions, while only $7.5 \%$ use desktops or laptops. Only $0.5 \%$ of students use other devices to attend online classes, such as tablets.

Table 1: Personal Profile of the Respondents

\begin{tabular}{|l|l|r|r|}
\hline \multicolumn{1}{|c|}{ Variable } & \multicolumn{1}{c|}{ Options } & \multicolumn{1}{c|}{ N } & \multicolumn{1}{c|}{$\%$} \\
\hline \multirow{3}{*}{ Gender } & Male & 173 & $45 \%$ \\
\cline { 2 - 4 } & Female & 212 & $55 \%$ \\
\hline \multirow{3}{*}{ Education Level } & UG & 327 & $85 \%$ \\
\cline { 2 - 4 } & PG & 58 & $15 \%$ \\
\hline \multirow{4}{*}{ Location } & Rural & 85 & $22 \%$ \\
\cline { 2 - 4 } & Suburban & 12 & $12 \%$ \\
\cline { 2 - 4 } & Urban & 66 & $66 \%$ \\
\hline
\end{tabular}




\begin{tabular}{|l|l|r|r|}
\hline \multirow{3}{*}{ Device Type } & Smartphones & 354 & $92 \%$ \\
\cline { 2 - 4 } & Desktop/Laptop & 29 & $7.5 \%$ \\
\cline { 2 - 4 } & Others & 2 & $0.5 \%$ \\
\hline
\end{tabular}

\subsection{Impact of Online Education on Physical Health:}

Students can improve their overall physical and mental fitness and reduce the risk of obesity, cardiovascular disorders, type 2 diabetes, hypertension, etc. by engaging in regular physical activities. Adequate workouts can strengthen the respiratory system, heart, bones, and muscles [53]. Students are one of the key groups kept in complete isolation during the lockdown as a result of the widespread COVID-19 pandemic, as all educational institutions were compelled to close and continue with online education. When asked how many hours of physical activity they undertook each day during the period of lockdown and online education, 33\% of students said they spent less than 1 hour per day. A moderate $45 \%$ of students engage in 1-2 hours of physical activity each day, and only $22 \%$ engaging in more than 2 hours per day. In comparison to their male counterparts, female students spend more time engaging in physical activities. Female students engage in more than 2 hours of physical activity per day, according to $28 \%$ of them. In the case of male students, it was only $17 \%$. Adults should participate in at least 150-300 minutes of moderate-intensity aerobic physical activity or 75-150 minutes of intense aerobic physical activity per day, or an equivalent combination of moderate and vigorous-intensity, according to WHO standards. According to the report, a large number of students are below the WHO benchmark. This invariably causes a slew of issues with students. Related details are given in Figure-2 below.

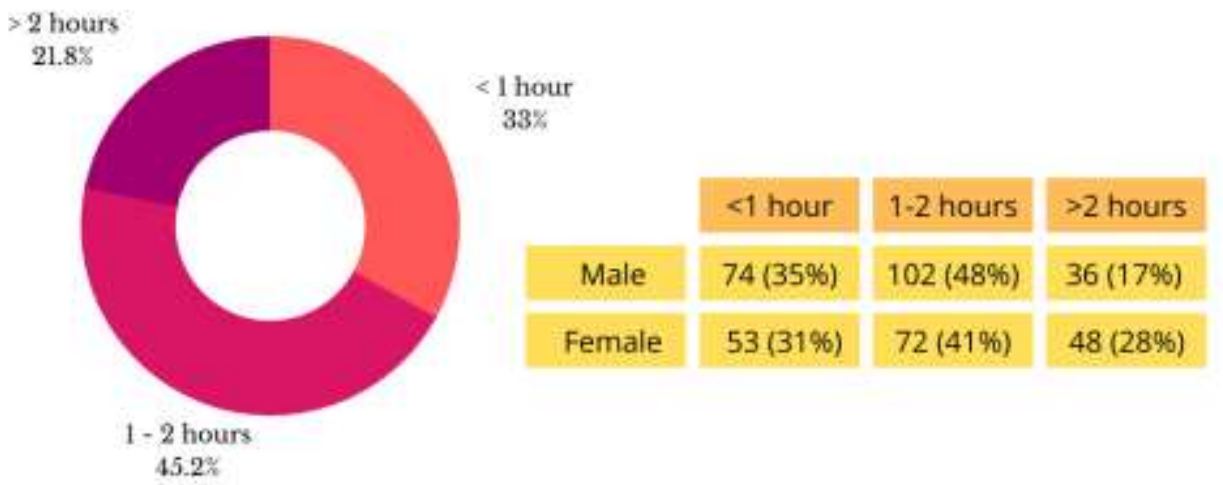

Fig. 2: Hours set aside by students for physical activities during COVID-19 lockdown.

Since online education is delivered through digital platforms, students are more likely to use electronic devices and spend a significant amount of time in front of a screen. Students spend a lot of time with their gadgets. Due to the stringent rules to contain the spread of the COVID-19, students were made to sit at home. As a result of this, there was a significant spike in their online activities. These unlimited online activities have a negative impact on their health. When it comes to children, there is a specific standard on their screen time but in the case of adults, there is no such hard and fast rule; excess of screen time will be dangerous. Reid Health discovered if the screen time is more than six hours it will cause eye pain, depression, etc. It also discovered that when social media activities are restricted to one hour or less, there is a significant improvement in the physical, mental and emotional wellbeing of individuals. Also, the overwhelming information displayed on the screen causes sleep disorders, depression, and anxiety, obesity, violence, lack of social skills, and lower physical activity levels are just a few of the negative effects of too much screen time. According to the survey, as shown in Figure-3 below, $47.8 \%$ of students spend 1-3 hours per day in front of the screen to participate in online education. $27.8 \%$ of students spend 4-6 hours each day in front of a screen, $8.8 \%$ spend more than 6 hours per day and $15.6 \%$ of students spend less than an hour. 


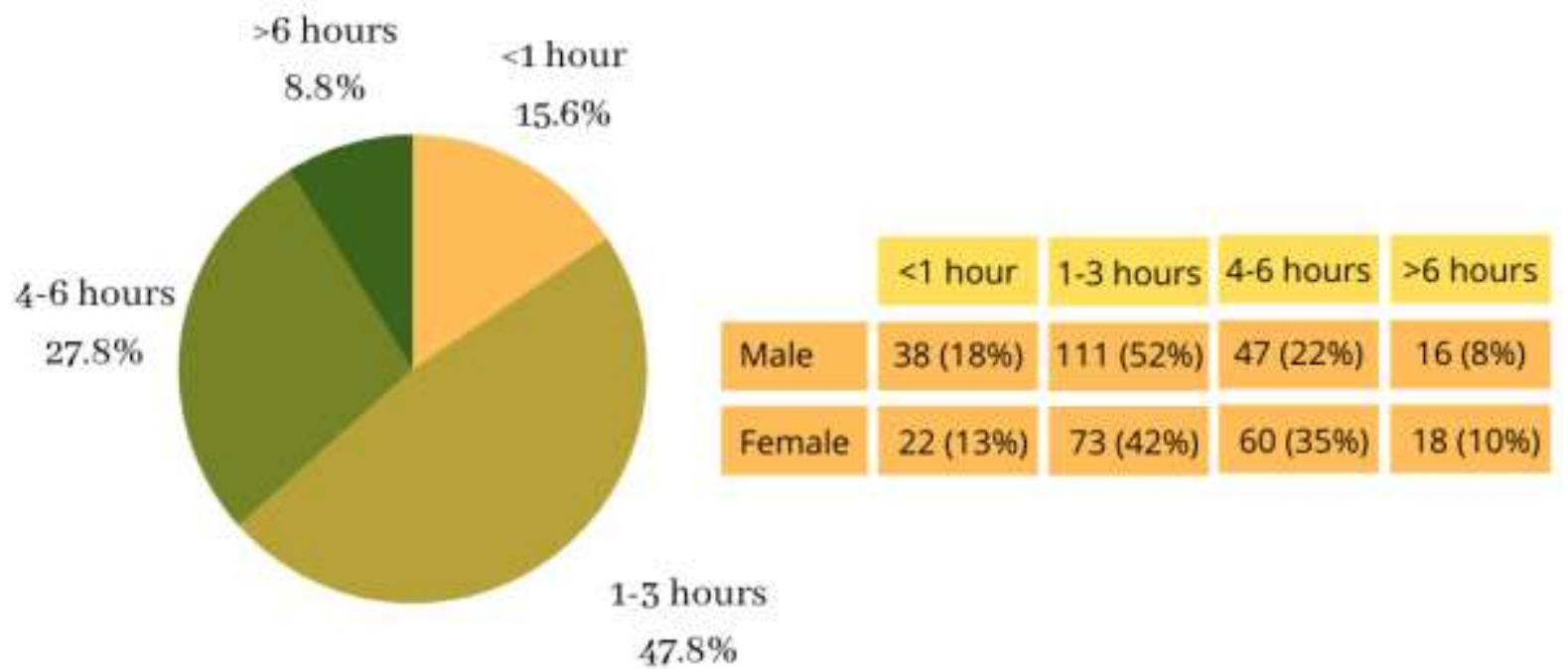

Fig. 3: Students' screen time per day.

Digital eye strain (DES) is a collection of vision-related disorders caused by prolonged computer, tablet, ereader, and mobile phone use. When viewing digital screens for long periods, many people develop eye irritation and eyesight issues. The length of time spent in front of a digital screen appears to enhance the level of discomfort. The eyes have to work harder when viewing a computer or digital screen. As a result, many individuals are susceptible to developing vision-related problems due to the specific characteristics and high visual demands of computer and digital screen viewing. The most common symptoms of DES that students are experiencing are headache, watering/tearing, and itching in the eyes, as shown in Table- 2 below. $77 \%$ of students experienced headaches on a regular or irregular basis. Watering/tearing in the eyes was experienced by $62 \%$ of students, while itching in the eyes was experienced by $56 \%$ of students.

Table 2: Digital eye strain (DES) experience of the students

\begin{tabular}{|l|r|r|r|r|r|}
\hline \multicolumn{1}{|c|}{ Options } & $\begin{array}{c}\text { Always of } \\
\text { moderate- } \\
\text { intensity }\end{array}$ & $\begin{array}{c}\text { Always of } \\
\text { severe } \\
\text { intensity }\end{array}$ & Never & $\begin{array}{c}\text { Occasionall } \\
\text { y of } \\
\text { moderate- } \\
\text { intensity }\end{array}$ & $\begin{array}{c}\text { Occasionall } \\
\text { y of severe } \\
\text { intensity }\end{array}$ \\
\hline Burning in Eyes & $4.42 \%$ & $3.12 \%$ & $55.32 \%$ & $29.61 \%$ & $7.53 \%$ \\
\hline Itching in Eyes & $6.75 \%$ & $4.42 \%$ & $43.64 \%$ & $38.44 \%$ & $6.75 \%$ \\
\hline Foreign Body Sensation in Eyes & $2.60 \%$ & $1.82 \%$ & $73.77 \%$ & $17.66 \%$ & $4.16 \%$ \\
\hline Watering/Tearing in Eyes & $7.27 \%$ & $4.16 \%$ & $38.18 \%$ & $42.08 \%$ & $8.31 \%$ \\
\hline Excessive Blinking of Eyes & $4.16 \%$ & $3.38 \%$ & $59.22 \%$ & $27.27 \%$ & $5.97 \%$ \\
\hline Redness in Eyes & $4.42 \%$ & $4.16 \%$ & $61.56 \%$ & $23.64 \%$ & $6.23 \%$ \\
\hline Pain in Eyes & $7.79 \%$ & $3.38 \%$ & $51.43 \%$ & $30.39 \%$ & $7.01 \%$ \\
\hline Feeling of Dryness in Eyes & $3.64 \%$ & $3.38 \%$ & $67.53 \%$ & $20.78 \%$ & $4.68 \%$ \\
\hline Blurring of Vision & $6.49 \%$ & $4.16 \%$ & $56.62 \%$ & $25.97 \%$ & $6.75 \%$ \\
\hline Double Vision & $2.08 \%$ & $2.34 \%$ & $76.36 \%$ & $15.32 \%$ & $3.90 \%$ \\
\hline Difficulty in Focusing Near & $6.23 \%$ & $2.86 \%$ & $62.08 \%$ & $24.42 \%$ & $4.42 \%$ \\
\hline Halos Around Objects & $2.60 \%$ & $2.34 \%$ & $77.66 \%$ & $14.29 \%$ & $3.12 \%$ \\
\hline Increased Sensitivity to Light & $5.71 \%$ & $4.16 \%$ & $55.58 \%$ & $28.05 \%$ & $6.49 \%$ \\
\hline Headache & $8.31 \%$ & $14.29 \%$ & $22.60 \%$ & $45.97 \%$ & $8.83 \%$ \\
\hline
\end{tabular}

Blue light emitted by computers, cellphones, tablets, televisions, and other electronic gadgets may cause eyesight damage in students. In this digital age, too much screen time is a typical mistake that can induce eyestrain in some students. Over time, exposure to blue light may cause substantial, long-term eye damage. As shown in Table-3, around 56\% of students attending online education have a vision problem of moderate to severe level regularly or on occasion. when compared to their male counterparts, the screen time of female students is more. as a result, they have more vision problems with $58 \%$ of female students having vision 
problems compared to $53 \%$ of male students. $37.40 \%$ of students notice moderate-intensity vision deterioration occasionally, $10.13 \%$ notice severe intensity occasionally, $5.71 \%$ notice moderate intensity regularly, and $2.86 \%$ notice severe intensity vision deterioration regularly.

Table 3: Students view towards vision deterioration due to online education

\begin{tabular}{|c|c|c|c|c|c|c|}
\hline \multirow[b]{2}{*}{ Options } & \multicolumn{2}{|c|}{ Female } & \multicolumn{2}{|c|}{ Male } & \multicolumn{2}{|c|}{ Total } \\
\hline & $\begin{array}{c}\text { Frequenc } \\
\mathbf{y}\end{array}$ & $\%$ & $\begin{array}{c}\text { Frequenc } \\
\mathbf{y}\end{array}$ & $\%$ & $\begin{array}{c}\text { Frequenc } \\
\mathbf{y}\end{array}$ & $\%$ \\
\hline Always of moderate-intensity & 12 & 5.66 & 10 & 5.78 & 22 & 5.71 \\
\hline Always of severe intensity & 8 & 3.77 & 3 & 1.73 & 11 & 2.86 \\
\hline Never & 88 & 41.51 & 81 & 46.82 & 169 & 43.90 \\
\hline Occasionally of moderate-intensity & 79 & 37.26 & 65 & 37.57 & 144 & 37.40 \\
\hline Occasionally of severe intensity & 25 & 11.79 & 14 & 8.09 & 39 & 10.13 \\
\hline
\end{tabular}

As online learners, students spend several hours each day working on coursework on a laptop, desktop computer, or smartphone. Because this has been their practice during recent days, many of them are not concerned or not aware of the harmful health risks associated with their practice. Leaning back or stretching forward for a long period causes discomfort in their shoulders, back, and muscles. Students may feel that their online activity is stressful as it causes them some sort of fatigue, headache, and pricking pain in some parts of their body. All these are because of their bad posture, use of unergonomic furniture. As a result of this, they lose focus in studies and display an impaired performance. As seen in Figure-4, 58.7\% of students agree that online education is causing back pain. Back pain has nothing to do with online education, according to $16.6 \%$ of students. $24.7 \%$ of students are unsure whether or not online education has an impact on student back discomfort.
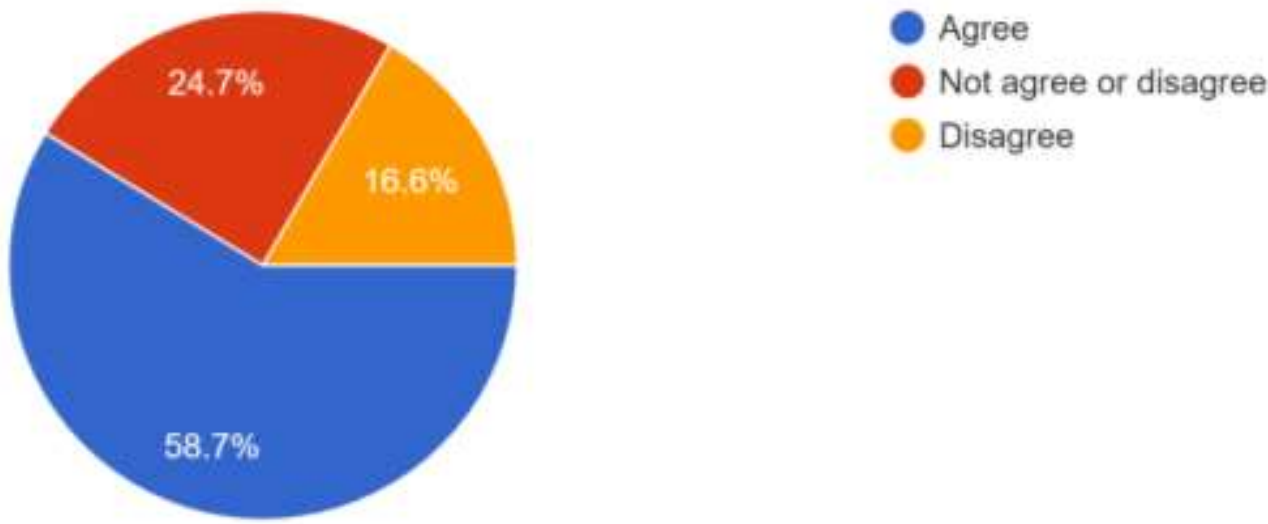

Fig. 4: Students response about back pain due to online education

Due to the restrictions on grocery shopping and lockdown/seal down conditions practiced to contain the spread of the COVID-19 pandemic many people started stockpiling food. Sitting glued at one place for their digital learning, boredom caused due to quarantine/home isolation, stress caused because of stringent deadlines for submission of assignments, etc. are directly linked with an excess of eating. The panic created by watching/reading news about the COVID-19, fear of death of near and dear ones, etc. made them eat more and more. The calorie intake case much more than the prescribed because the 'comfort food' is rich in sugar, oil/ghee, carbohydrates. Some spicy snacks contained an excess of salt too. These food items boost the mood of the students as they are rich in sugar and carbs. Eating an excess of food to overcome boredom is called 'emotional eating', 'over eating', 'lonely eating', etc. Whatever be the name the ultimate cause of this is a phenomenal gain in body weight which in turn causes obesity and cardiovascular disorders.

As there was very limited access to grocery shopping during the lockdown, fear of catching the COVID-19 pandemic people and limited availability of fresh fruits and vegetables people started buying processed food items that have a longer shelf-life. The processed food is rich in calories too. Following an unbalanced diet, less frequent physical activities and the sedentary nature of online learning made the students more gain more weight. In addition to this, the moods of a person have a direct impact on the consumption of food. A result of stress, boredom, isolation, and abundant availability of packed or canned food made the students eat more. As Figure-5 shows below, during online education, students have developed the habit of eating more than the

Krishna Prasad K., et al., (2021); www.srinivaspublication.com 
recommended four meals per day, compared with their normal consumption in on-campus classes. $60 \%$ of students agree that at lock-down, they used to eat more. $43 \%$ of students say they began to eat somewhat more during online education, $9 \%$ say it is moderate and $8 \%$ agree that they are extremely affected by food habits.

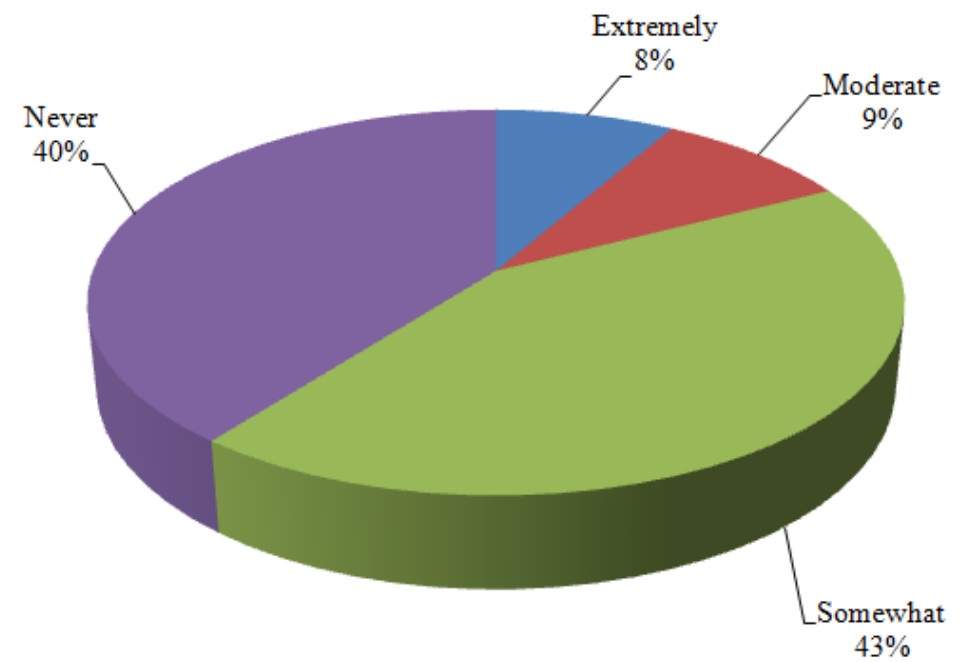

Fig. 5: Students' response to change in food habits during online education.

Figure-6 shows how students' habit of eating more food directly affects their weight gain while online education. $67.5 \%$ of students believe that their body weight has changed in the course of online classes. $38.2 \%$ of students say they noticed a slight increase in weight, $10.9 \%$ noticed a moderate increase and $18.5 \%$ noticed a very large increase in weight.
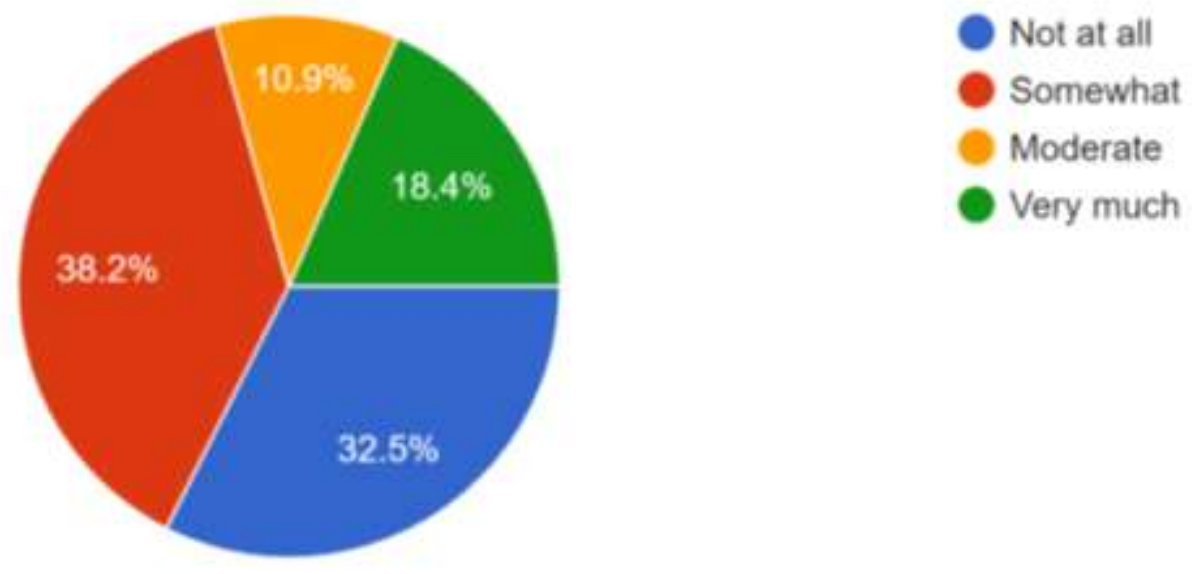

Fig. 6: Students' response to change in their body weight before and after lockdown.

\subsection{Impact of Online Education on Mental Health:}

Good sleep is an essential component of one's health. Sleep is considered important because it keeps the body fit and ready for the activities of the next day. For students, it is the most essential factor as it enhances their concentration and cognition level. Lack of sleep affects both the physical and mental health of an individual. It has a greater impact on the body's immune system. Experts suggest that young adults should have more than seven hours of sleep per day to keep their minds relaxed and body fit and healthy [56]. A person who sleeps less will not be able to concentrate on studies. Sleeplessness can also lead to obesity, an increase in blood pressure, and even depression. Furthermore, sleeplessness causes fatigue and mood swings. Due to this, students feel too exhausted during online classes. Table-4 below lists the sleeping habits of students. It indicates that more than $55.06 \%$ of students experience physical/mental fatigue and sleepiness during online classes. this may be because of a change in their sleep pattern or increased screen time. Only $25.19 \%$ of students opined that their sleeping patterns have not at all altered during the lockdown period and the majority among the rest that is $39.22 \%$ agree that they experience a change in the sleeping pattern. $51.43 \%$ of students agree that they sleep for 6-7 hours a day and some $38.44 \%$ of students sleep for 8-9 hours. And $8.75 \%$ of students sleep less than 5 hours per day. 
Table 4: Students' response about sleep time and sleep pattern during online learning.

\begin{tabular}{|l|r|r|r|}
\hline \multicolumn{1}{|c|}{ Options } & \multicolumn{1}{c|}{ Female } & \multicolumn{1}{c|}{ Male } & \multicolumn{1}{c|}{ Total } \\
\hline Hours of sleep have you been provided every day \\
\hline$<5$ hours & $8.49 \%$ & $8.67 \%$ & $8.57 \%$ \\
\hline$>9$ hours & $2.36 \%$ & $0.58 \%$ & $1.56 \%$ \\
\hline 6 -7 hours & $49.53 \%$ & $53.76 \%$ & $51.43 \%$ \\
\hline 8-9 hours & $39.62 \%$ & $36.99 \%$ & $38.44 \%$ \\
\hline Experience of fatigue/sleepiness during the online classes \\
\hline No & $42.45 \%$ & $47.98 \%$ & $44.94 \%$ \\
\hline Yes & $57.55 \%$ & $52.02 \%$ & $55.06 \%$ \\
\hline Experience of change in sleep pattern during lockdown period \\
\hline Extremely & $4.25 \%$ & $6.94 \%$ & $5.45 \%$ \\
\hline Moderate & $17.45 \%$ & $13.87 \%$ & $15.84 \%$ \\
\hline Never & $25.94 \%$ & $24.28 \%$ & $25.19 \%$ \\
\hline Somewhat & $42.45 \%$ & $35.26 \%$ & $39.22 \%$ \\
\hline Very & $9.91 \%$ & $19.65 \%$ & $14.29 \%$ \\
\hline
\end{tabular}

Students experience different types of stress during online classes. many students have self-reported illnesses and all these have a huge impact on their academic achievements. Due to stress students tend to lose motivation in turn will not be able to concentrate much on their learning activities. When they drop their focus, they will lose interest to attend classes. extreme stress may also lead to anxiety, sleep disorders, and even addiction. Table-5 lists different types of stressful experiences during online learning. Among female students, $42.92 \%$ opine that they are stressed because of stringent deadlines in their academic activities and $24.06 \%$ are worried about the development challenges and $15.09 \%$ feel social mistreatment is causing them more stress. About their level of anxiety during online learning, $32 \%$ of female students are worried more about their future, $25 \%$ are worried about the worst thing happening during COVID-19, $11.79 \%$ have fear of losing their near and dear ones. Among male students $37.57 \%$ have time pressures, $30.06 \%$ of them are stressed about their development challenges $12.72 \%$ are worried about academic alienation and $11.56 \%$ are tensed about social mistreatment. As far as anxiety is concerned, $40.6 \%$ of male students are worried about their future $13.29 \%$ are nervous during the COVID-19 pandemic, $12.14 \%$ are worried about the worst thing happening shortly.

Table 5: Students' response about the level of stress and anxiety during online learning.

\begin{tabular}{|c|c|c|}
\hline Options & Female & Male \\
\hline \multicolumn{3}{|l|}{ Recent stressful experiences } \\
\hline Academic alienation & $11.32 \%$ & $12.72 \%$ \\
\hline Development challenge & $24.06 \%$ & $30.06 \%$ \\
\hline Friendship problems & $6.60 \%$ & $8.09 \%$ \\
\hline Social mistreatment & $15.09 \%$ & $11.56 \%$ \\
\hline Time pressures & $42.92 \%$ & $37.57 \%$ \\
\hline \multicolumn{3}{|c|}{ Level of anxiety during the COVID-19 pandemic } \\
\hline Difficulty in breathing & $0.47 \%$ & $3.47 \%$ \\
\hline Fear of death & $3.77 \%$ & $7.51 \%$ \\
\hline Fear of losing control & $3.30 \%$ & $5.20 \%$ \\
\hline Fear of losing your relative & $11.79 \%$ & $7.51 \%$ \\
\hline Fear of worst happening & $25.00 \%$ & $12.14 \%$ \\
\hline Feeling of choking & $0.00 \%$ & $1.16 \%$ \\
\hline Future anxiety & $32.08 \%$ & $40.46 \%$ \\
\hline Nervous & $8.49 \%$ & $13.29 \%$ \\
\hline Scared & $13.21 \%$ & $8.09 \%$ \\
\hline Terrified & $1.89 \%$ & $1.16 \%$ \\
\hline
\end{tabular}

Online learning creates so much stress among students. It is common that whenever people experience some sort of stress, they need to take a break from their online activity. Hobbies are activities that are meant for 
people to relax. Hobbies provide a much-needed break from stressful monotonous activities. A person who involves in one or the other hobby is less susceptible to physical or mental stress. Involving in hobbies gives positive feelings and reduces depression and negative thoughts to a great extent. Hobbies are most essential for students who are overwhelmed with online activities. This study revealed that there is a gender gap in the stress-busting activities followed by students. Listening to music is the most preferable stress-busting activities that are followed by a majority of students according to nearly $30 \%$ of the respondents among that $22 \%$ are female students. Also, female students consider painting, drawing, sleeping, cooking,

\subsection{Impact of Online Education on Emotional Health:}

Motivation, creativity, involvement, and teamwork are considered key factors of the learning process. Most of the researchers have identified that there is less scope for these aspects during online learning. Extensive use of technology disconnects students from nature, physical activities, family members, and friends. A student who spends more time in the virtual world is likely to interact less this results in the emotional imbalance of young adults. Due to social isolation and stress involved in online learning students start experiencing one or the other issues related to their emotional health. All these health issues act as a hindrance to their learning process.

It is a well-known fact the students are required to sit in front of a gadget to attend their online classes. A majority of them are neither concerned much about the adverse effect of their online activities on their health, nor they are much concerned about the same. At one point in time, they start experiencing one or the other problem. Individual students' motivation to put out effort in a study can be hampered by mental or physical health issues and other personal issues [57]. Skipping classes, turning up late, dozing in the classroom, neglecting homework, not answering queries during sessions, and a change in behavior or temperament are all psychological indicators of personal concerns that might lower energy levels. Table- 6 below indicates different types of issues related to the emotions of students during online classes [58]. it indicates that students are not always worried about their issues but sometimes during their online classes, they worry more about the issues related to their study, their physical health, similar unprecedented issues that may occur in near future their mental health because of the adverse effects of online classes and then their family and relationship [59]. The data in Table-6 is summarized in Figure-7.

Table 6: Students' responses on different issues related to emotions during online classes.

\begin{tabular}{|l|r|r|r|r|r|}
\hline \multicolumn{1}{|c|}{ Options } & $\begin{array}{c}\text { A good } \\
\text { part of the } \\
\text { time }\end{array}$ & $\begin{array}{c}\text { A little of } \\
\text { the time }\end{array}$ & $\begin{array}{c}\text { All of the } \\
\text { time }\end{array}$ & $\begin{array}{c}\text { Most } \\
\text { of the } \\
\text { time }\end{array}$ & $\begin{array}{c}\text { Some of } \\
\text { the time }\end{array}$ \\
\hline Personal physical health & $14.81 \%$ & $31.69 \%$ & $7.53 \%$ & $15.32 \%$ & $30.65 \%$ \\
\hline Personal mental health & $17.92 \%$ & $34.55 \%$ & $8.05 \%$ & $13.77 \%$ & $25.71 \%$ \\
\hline Studying issues & $20.78 \%$ & $14.55 \%$ & $13.25 \%$ & $19.48 \%$ & $31.95 \%$ \\
\hline Future education & $22.08 \%$ & $11.95 \%$ & $21.82 \%$ & $25.19 \%$ & $18.96 \%$ \\
\hline Family and relationship & $24.68 \%$ & $20.00 \%$ & $14.03 \%$ & $15.84 \%$ & $25.45 \%$ \\
\hline Professional career in the future & $27.01 \%$ & $11.17 \%$ & $22.86 \%$ & $22.34 \%$ & $16.62 \%$ \\
\hline Similar pandemic crisis in the future & $20.26 \%$ & $24.42 \%$ & $11.17 \%$ & $17.14 \%$ & $27.01 \%$ \\
\hline Leisure activities & $22.86 \%$ & $25.71 \%$ & $12.99 \%$ & $13.51 \%$ & $24.94 \%$ \\
\hline
\end{tabular}




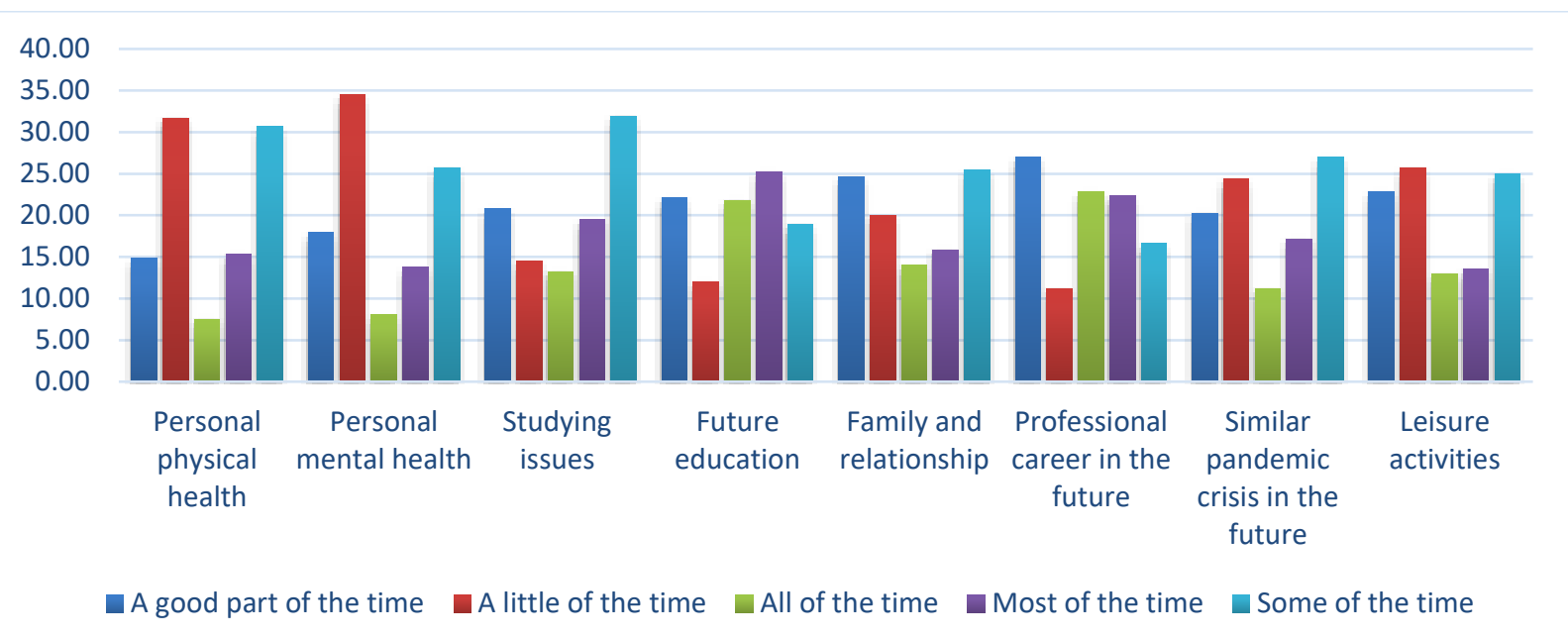

Fig. 7: Graphical presentation of different issues related to emotions during online classes

The correlation between emotions and learning is irreversible. Emotions play an important impact on cognitive abilities like attentiveness, perseverance, and memory. If students are satisfied with their online learning experience, they will express positive emotions such as joy, pride, and hope; but, if the learning process is challenging, they will express negative emotions such as anger, frustration, boredom, and anxiety. Table-7 shows different emotions of students when attending online classes. A majority of them occasionally experience negative emotions during online learning.

Table 7: Students' responses to different emotional parameters during online classes.

\begin{tabular}{|l|r|r|r|r|r|}
\hline \multicolumn{1}{|c|}{ Options } & Always & \multicolumn{1}{c|}{ Never } & \multicolumn{1}{c|}{ Often } & Rarely & Sometimes \\
\hline Joyful & $6.75 \%$ & $21.56 \%$ & $9.61 \%$ & $29.35 \%$ & $32.73 \%$ \\
\hline Hopeful & $9.61 \%$ & $14.81 \%$ & $12.99 \%$ & $27.27 \%$ & $35.32 \%$ \\
\hline Frustrated & $9.61 \%$ & $16.10 \%$ & $15.58 \%$ & $29.09 \%$ & $29.61 \%$ \\
\hline Angry & $8.31 \%$ & $19.22 \%$ & $14.29 \%$ & $25.45 \%$ & $32.73 \%$ \\
\hline Anxious & $7.53 \%$ & $18.18 \%$ & $13.77 \%$ & $29.09 \%$ & $31.43 \%$ \\
\hline Hopeless & $8.83 \%$ & $28.31 \%$ & $9.87 \%$ & $24.94 \%$ & $28.05 \%$ \\
\hline Bored & $15.84 \%$ & $12.99 \%$ & $18.70 \%$ & $18.96 \%$ & $33.51 \%$ \\
\hline Relieved & $4.94 \%$ & $18.70 \%$ & $12.73 \%$ & $32.73 \%$ & $30.91 \%$ \\
\hline Proud & $10.91 \%$ & $21.56 \%$ & $11.69 \%$ & $24.16 \%$ & $31.69 \%$ \\
\hline
\end{tabular}

In addition to being a global health catastrophe, the COVID-19 pandemic has several psychological, emotional, and socioeconomic consequences [60]. A phobia is a strong aversion to a specific object, activity, or circumstance. The present COVID-19 pandemic has created psychological fears, such as having a few COVID-19 symptoms. For no identifiable reason, some people experience dizziness, a loss of appetite, and breathing difficulties. It has also instilled in them a fear of dying. Students are either afraid of dying as a result of COVI-19 or of losing their loved ones as a result of COVID-19. People's behavior changes, such as their fear of contacting an object, the fear of being in open or confined spaces [61], and their concern of attending public gatherings are frequently observed these days. Students' fear and worries related to COVID-19 are recorded in Table-8. it shows that female students tend to worry more about COVID-19 than male students.

Table 8: Students' response to COVID-19 concerns.

\begin{tabular}{|l|r|r|}
\hline \multicolumn{1}{|c|}{ Options } & \multicolumn{1}{c|}{ Female } & \multicolumn{1}{c|}{ Male } \\
\hline Afraid of contracting COVID-19 \\
\hline Extremely & $6.60 \%$ & $8.09 \%$ \\
\hline Moderate & $16.51 \%$ & $18.50 \%$ \\
\hline Never & $20.75 \%$ & $33.53 \%$ \\
\hline Somewhat & $45.28 \%$ & $27.75 \%$ \\
\hline
\end{tabular}




\begin{tabular}{|l|r|r|}
\hline Very & $10.85 \%$ & $12.14 \%$ \\
\hline worried are you that a family member will contract COVID-19 \\
\hline Extremely & $19.34 \%$ & $19.08 \%$ \\
\hline Moderate & $17.45 \%$ & $19.65 \%$ \\
\hline Never & $12.26 \%$ & $15.61 \%$ \\
\hline Somewhat & $28.77 \%$ & $26.01 \%$ \\
\hline Very & $22.17 \%$ & $19.65 \%$ \\
\hline Emotions about the COVID-19 \\
\hline Afraid & $11.32 \%$ & $12.14 \%$ \\
\hline Indifferent & $11.32 \%$ & $15.03 \%$ \\
\hline Sad & $22.64 \%$ & $24.28 \%$ \\
\hline Temporary & $10.85 \%$ & $20.81 \%$ \\
\hline Worried & $43.87 \%$ & $27.75 \%$ \\
\hline
\end{tabular}

\section{TESTING OF HYPOTHESIS :}

Using a One-way ANOVA statistical model, the hypotheses were tested. One-way ANOVA ("Variance Analysis") compares the means of two or more independent groups to determine if there is statistical evidence of significant differences in the associated population means. "The one-way ANOVA compares the means between the groups of data and determines whether any of those means are statistically significantly different from each other. Specifically, it tests the null hypothesis:

$$
H_{0}: \mu_{1}=\mu_{2}=\mu_{3}=\cdots=\mu_{k}
$$

where $\mu=$ group mean and $k=$ number of groups. If, however, the one-way ANOVA returns a statistically significant result, we accept the alternative hypothesis (HA), which is that there are at least two group means that are statistically significantly different from each other". The One-Way ANOVA Calculator, Including Tukey HSD provided by Social Science Statistics (https://www.socscistatistics.com/tests/anova/default2.aspx) is used to perform the test with data samples.

\section{$\mathrm{H}_{1}$ : Online education has a significant impact on students' eye health}

\begin{tabular}{|l|l|l|l|l|}
\hline \multicolumn{5}{|c|}{ Result Details } \\
\hline \multicolumn{1}{|c|}{ Source } & \multicolumn{1}{c|}{$\boldsymbol{S S}$} & \multicolumn{1}{c|}{$\boldsymbol{d f}$} & \multicolumn{1}{c|}{$\boldsymbol{M S}$} & \\
\hline Between-treatments & 437857.5714 & 4 & 109464.3929 & $F=109.4199$ \\
\hline Within-treatments & 65026.4286 & 65 & 1000.4066 & \\
\hline Total & 502884 & 69 & & \\
\hline
\end{tabular}

The One-Way ANOVA test is conducted at a 5\% level of confidence with $4\left(\mathrm{~V}_{1}\right), 69\left(\mathrm{~V}_{2}\right)$ degrees of freedom. The critical f-ratio value is 109.4199. The $p$-value is $<.00001$. The result is significant at $p<.05$. Hence the alternate hypotheses were accepted.

$\mathrm{H}_{2}$ : There was no significant change in the students' habit frequency before or during the COVID-19 pandemic.

\begin{tabular}{|l|l|l|l|l|}
\hline \multicolumn{5}{|c|}{ Result Details } \\
\hline \multicolumn{1}{|c|}{ Source } & \multicolumn{1}{c|}{$\boldsymbol{S S}$} & $\boldsymbol{d f}$ & \multicolumn{1}{c|}{$\boldsymbol{M S}$} & \\
\hline Between-treatments & 16309.3333 & 4 & 4077.3333 & $F=2.43817$ \\
\hline Within-treatments & 117060.6667 & 70 & 1672.2952 & \\
\hline Total & 133370 & 74 & & \\
\hline
\end{tabular}

The One-Way ANOVA test is conducted at a 5\% level of confidence with $4\left(\mathrm{~V}_{1}\right), 69\left(\mathrm{~V}_{2}\right)$ degrees of freedom. The critical f-ratio value is 2.43817 . The $p$-value is $<.054952$. The result is not significant at $p>.05$. Hence the alternate hypotheses were rejected. 
$H_{3}$ : Students suffered greatly during the lockdown of COVID-19 under stress and anxiety

\begin{tabular}{|l|l|l|l|l|}
\hline \multicolumn{5}{|c|}{ Result Details } \\
\hline \multicolumn{1}{|c|}{ Source } & \multicolumn{1}{c|}{$\boldsymbol{S S}$} & \multicolumn{1}{c|}{$\boldsymbol{M S}$} & \multicolumn{1}{c|}{$\boldsymbol{M S}$} & \\
\hline Between-treatments & 8610.25 & 4 & 2152.5625 & $F=4.26666$ \\
\hline Within-treatments & 17657.75 & 35 & 504.5071 & \\
\hline Total & 26268 & 39 & & \\
\hline
\end{tabular}

The One-Way ANOVA test is conducted at a 5\% level of confidence with $4\left(\mathrm{~V}_{1}\right), 39\left(\mathrm{~V}_{2}\right)$ degrees of freedom. The critical f-ratio value is 4.26666 . The $p$-value is $<.006454$. The result is not significant at $p<.05$. Hence the alternate hypotheses were accepted.

$H_{4}$ : The students were under academic stress and poor emotional wellness during online training because of the COVID 19 pandemic.

\begin{tabular}{|l|l|l|l|l|}
\hline \multicolumn{5}{|c|}{ Result Details } \\
\hline \multicolumn{1}{|c|}{ Source } & \multicolumn{1}{c|}{$\boldsymbol{S S}$} & \multicolumn{1}{c|}{$\boldsymbol{d f}$} & \multicolumn{1}{c|}{$\boldsymbol{M S}$} & \\
\hline Between-treatments & 46545.5556 & 4 & 11636.3889 & $F=67.55088$ \\
\hline Within-treatments & 6890.4444 & 40 & 172.2611 & \\
\hline Total & 53436 & 44 & & \\
\hline
\end{tabular}

The One-Way ANOVA test is conducted at a 5\% level of confidence with $4\left(\mathrm{~V}_{1}\right), 44\left(\mathrm{~V}_{2}\right)$ degrees of freedom. The critical f-ratio value is 67.55088 . The $p$-value is $<.00001$. The result is not significant at $p<.05$. Hence the alternate hypotheses were accepted.

\section{PERCEPTION OF STUDENTS ON ONLINE EDUCATION :}

Online education is the only way to keep up with education in this pandemic situation. Thanks to Internet and web technologies. The entire academic year 2020-21 went by with few academic events on campus. Educators give education from their places of work and residence via online platforms. At the same time, students participate in the learning process from the comfort of their own homes. Online education allows students to receive instruction without having to travel, and it is also more flexible. Many teachers are taking advantage of the situation by trying out new teaching and assessment methods. This instills hope. However, as online education becomes the exclusive mode of instruction for an extended length of time, the good, bad, and ugly aspects of online education become apparent. Even though teachers and students have become accustomed to online learning in this pandemic situation, they appear to be dissatisfied with how it is proceeding. Oncampus classroom-based education, students say, is more effective and convenient than online learning. They strongly believe they learn less and are more stressed when learning online. Table- 11 below gives a view of the sentiments of the students in this pandemic period on the perception of online education.

Table 11: The extent of students' agreement on the current teaching and learning environment.

\begin{tabular}{|l|c|c|c|c|c|}
\hline \multicolumn{1}{|c|}{ Options } & Agree & Disagree & Neutral & $\begin{array}{c}\text { Strongly } \\
\text { Agree }\end{array}$ & $\begin{array}{c}\text { Strongly } \\
\text { disagree }\end{array}$ \\
\hline $\begin{array}{l}\text { In comparison to onsite study, I find it more } \\
\text { difficult to concentrate while online learning. }\end{array}$ & $28.05 \%$ & $11.43 \%$ & $27.53 \%$ & $23.12 \%$ & $9.87 \%$ \\
\hline $\begin{array}{l}\text { Since on-site classes were withdrawn, my } \\
\text { academic performance has improved. }\end{array}$ & $12.21 \%$ & $31.43 \%$ & $29.09 \%$ & $5.45 \%$ & $21.82 \%$ \\
\hline $\begin{array}{l}\text { Since the cancellation of on-site classes, my } \\
\text { academic performance has deteriorated. }\end{array}$ & $21.82 \%$ & $23.64 \%$ & $31.43 \%$ & $12.99 \%$ & $10.13 \%$ \\
\hline $\begin{array}{l}\text { I have adapted nicely to my new learning } \\
\text { environment. }\end{array}$ & $20.52 \%$ & $23.90 \%$ & $36.36 \%$ & $4.94 \%$ & $14.29 \%$ \\
\hline $\begin{array}{l}\text { Even though there were very few on-site classes } \\
\text { this year, I was able to learn the skills given in } \\
\text { class. }\end{array}$ & $22.08 \%$ & $18.18 \%$ & $38.44 \%$ & $9.61 \%$ & $11.69 \%$ \\
\hline $\begin{array}{l}\text { Since on-site sessions have been canceled, I have } \\
\text { been able to find out how to complete the most } \\
\text { challenging classwork. }\end{array}$ & $22.86 \%$ & $16.36 \%$ & $38.18 \%$ & $9.35 \%$ & $13.25 \%$ \\
\hline
\end{tabular}

\section{FINDINGS :}


COVID-19 has transformed into much more than a health emergency. It has created catastrophic social, financial, and political emergencies that will leave deep scars by focusing on all of the countries that are affected. Very often physical and mental health are considered as different aspects of human life but in reality, they go hand in hand. One has a greater influence on another. For example, too much stress and anxiety can reduce the immunity of a person. Too much exposure to mobile and laptop screens is currently one of the major disadvantages of online education and leads to a feeling of isolation and fear. It could signal unhappiness as well as an increase in odd or obsessive behaviors such as nail picking, thumb sucking, and hair-pulling. Excessive use of gadgets has been linked to mental health issues such as stress, anxiety, excitation, or thrill, headaches, muscular exhaustion, eye and ear strains, obesity or overweight, faintness, sleep patterns, mental disruption, back discomfort, shoulders, and neck muscles, among other things. Students' physical activity levels were also altered by online education, including improper postures, later bedtimes, longer sleep rise cessation, and later waking hours, all of which have been linked to sedentary and inactive lifestyles. Developing a positive attitude by family members can have a significant impact on the mental wellbeing of students. During the COVID-19 pandemic, those students with preexisting mental health concerns were very much vulnerable to the psychological impact of online learning.

The descriptive analysis of the findings of this survey study is listed below. Supporting statistics are given in Table-12 below.

- The participants generally knew very well the principal modes of COVID-19 transmission, common disease symptoms, and recovery from the infection. All knowledge questions in the survey have been correctly answered.

- Official sources of information were the most trusted, with $62.47 \%$ of students believing in them: the government $(57.66 \%)$ and medical experts $(67.27 \%)$. Non-official sources, on the other hand, are trusted by $33.37 \%$ of students: social media $(31.68 \%)$ and family and friends $(35.06 \%)$. The information provides by news websites is also plausible and trustworthy, according to $47.79 \%$ of students.

- Students' behavior changed dramatically as a result of COVID-19. Students are now more cautious about handwashing, not leaving the house for no reason, avoiding crowds and large gatherings, avoiding touching facial parts, shaking hands, trying to avoid tours and visits, attempting to avoid public transportation for travel, increased physical activity, stocking up on essentials, and, most importantly, wearing masks when going outside.

- Prolonged screen usage has been linked to an increase in vision difficulties as well as frequent headaches. In addition, anxiety and depression are on the rise as a result of home confinement, as are sleep difficulties. Students who take online classes from home are not required to be professional in the classroom. As a result, their physical health is worsening in numerous ways. Many students have noticed that their vision has deteriorated as a result of their constant use of a smartphone or computer screen. A substantial number of online students reported having headaches. More than half of the students reported itching and watering in their eyes. Burning eyes, excessive blinking, pain in the eyes, blurred vision, and increased sensitivity to light are just a few of the common eye-related symptoms that many online students experienced.

- Students are not able to follow good ergonomics at home, unlike in the classroom. One of the most prominent reasons for the recent rise in back problems is taking online classes on beds, sofas, floors, etc. in postures that aren't ergonomic. While attending classes online, more than half of the students (58.70\%) complained of back pain.

- Obesity is on the rise among students, either as a result of a lack of outdoor physical activity or as a result of binge eating and ready access to junk food at home. During the lockdown caused by COVID19, a large number of students developed the habit of eating more than the required four meals per day, and as a result, they noticed a change in body weight.

- During the lockdown period, students' sleeping patterns changed noticeably, which was reflected in their feelings of fatigue or sleepiness during online classes. Approximately $89 \%$ of students agree that their sleeping patterns have changed, and $55 \%$ believe they have experienced exhaustion or sleepiness while taking online classes.

- The majority of online students faced stress during their remote education. There could be a variety of reasons for this. Some people were stressed because of academic estrangement, while others were stressed because of developmental challenges. A few students were under pressure due to friendship 
issues. For many individuals, social mistreatment is a source of stress. Many of the students were under stress due to time constraints.

- Students' anxiety during their online education is primarily caused by their fear of the future and the worst-case eventuality. Students were less concerned about death, losing control, and losing their relatives as a result of the COVID-19 scare.

- 3/4 of students are concerned about catching COVID-19 either directly or through family members. $73.5 \%$ of students are terrified of catching COVID-19, and $86 \%$ are concerned that a family member will be infected.

Table-12: Descriptive statistics for observed indicators of COVID-19 knowledge, sources of information, behaviors, and health issues $(\mathrm{N}=385)$.

\begin{tabular}{|l|l|c|}
\hline Variable & Category & N (\%) \\
\hline $\begin{array}{l}\text { I. Statements of knowledge } \\
\text { (True / False) }\end{array}$ & $\begin{array}{l}\text { COVID-19 spreads through respiratory droplets of } \\
\text { infected people (T) } \\
\text { COVID-19's main clinical signs are fever, fatigue, } \\
\text { and dry cough (T) } \\
\text { There is an effective cure for COVID-19 (T) } \\
\text { Early detection and supportive treatment can help } \\
\text { most patients recover from the infection (T) } \\
\text { All COVID-19 infected individuals will develop } \\
\text { severe illness (F) }\end{array}$ & 361 (93.76) \\
The elderly with chronic disease are more likely to \\
be serious (T) \\
$\begin{array}{l}\text { If there is no fever, people with COVID-19 cannot } \\
\text { transmit the virus to others (F) } \\
\text { People must avoid going to crowded places to } \\
\text { prevent COVID-19 infection (T) } \\
\text { Isolation of COVID-19 infected persons is effective } \\
\text { means of reducing the spread of the virus } \\
\text { The measures to prevent COVID-19 infections } \\
\text { should be taken by young adults }\end{array}$ & 33618 (86.75) \\
\hline
\end{tabular}

\begin{tabular}{|l|l|c|}
\hline $\begin{array}{l}\text { II. Sources of Information } \\
\text { (Yes/No) }\end{array}$ & Official Sources & \\
& Government (Y) & $222(57.66)$ \\
& Health Professionals (Y) & $259(67.27)$ \\
& Unofficial Sources & \\
& Social Media (Y) & $122(31.68)$ \\
& Family and Friends (Y) & $135(35.06)$ \\
& News Websites (Y) & $184(47.79)$ \\
\hline
\end{tabular}

\section{Change in behaviors (Yes/No)}

\section{Washing hands (Y)}

Leaving the house for unnecessary reasons $(\mathrm{N})$

Avoid crowds and large gatherings (Y)

Avoided touching your face (Y)

Shaking hands $(\mathrm{N})$

Stocking up on essentials (Y)

Canceled travel ( $\mathrm{Y}$ )

Avoiding public transport (Y)

Wearing a mask outside $(\mathrm{Y})$

Recreation or workout (Y)
367 (95.32)

$217(56.36)$

$310(80.52)$

$332(86.23)$

$191(49.61)$

$278(72.21)$

$319(82.86)$

$319(82.86)$

$362(94.03)$

$303(78.70)$ 


\begin{tabular}{|l|l|l|}
\hline IV. Physical Health \& Related & Burning in Eyes (Y) & $172(44.67)$ \\
Attributes (Yes/No) & Itching in Eyes (Y) & $217(56.36)$ \\
& Foreign Body Sensation in Eyes (Y) & $101(26.23)$ \\
& Watering/Tearing in Eyes (Y) & $238(61.81)$ \\
& Excessive Blinking of Eyes (Y) & $157(40.77)$ \\
& Redness in Eyes (Y) & $148(38.44)$ \\
& Pain in Eyes (Y) & $187(48.57)$ \\
& Feeling of Dryness in Eyes (Y) & $125(32.46)$ \\
& The blurring of Vision (Y) & $167(43.37)$ \\
& Double Vision (Y) & $91(23.63)$ \\
& Difficulty in Focusing Near (Y) & $146(37.92)$ \\
& Halos Around Objects (Y) & $86(22.33)$ \\
& Increased Sensitivity to Light (Y) & $171(44.41)$ \\
& Headache (Y) & $298(77.40)$ \\
& Noticed vision deteriorating (Y) & $216(56.10)$ \\
& Felt back pain (Y) & $226(58.70)$ \\
& Developed the habit of eating more than the & $233(60.51)$ \\
& recommended four meals per day (Y) & \\
& Change in body weight before \&after lockdown (Y) & $260(67.53)$ \\
\hline
\end{tabular}

\section{Mental and Emotional Health \& Related Attributes (Yes/No)}

\begin{tabular}{|l|l|}
\hline Felt fatigue/sleepiness during the online classes (Y) & $212(55.06)$ \\
\hline Change in sleep pattern during lockdown period (Y) & $343(89.09)$ \\
\hline Stressful experiences during lockdown period & \\
Academic alienation (Y) & $46(11.94)$ \\
Development challenge (Y) & $103(26.75)$ \\
Friendship problems (Y) & $28(7.27)$ \\
Social mistreatment (Y) & $52(13.50)$ \\
Time pressures (Y) & $156(40.51)$ \\
\hline Level of anxiety during the COVID-19 pandemic & \\
Fear of death (Y) & $21(5.45)$ \\
Fear of losing control (Y) & $16(4.15)$ \\
Fear of losing your relative (Y) & $38(9.87)$ \\
Fear of worst happening (Y) & $74(19.22)$ \\
Future anxiety (Y) & $138(35.84)$ \\
Nervous (Y) & $41(10.65)$ \\
Scared (Y) & $42(10.90)$ \\
\hline Afraid of contracting COVID-19 (Y) & $283(73.50)$ \\
\hline Worried that a family member will contract & $332(86.23)$ \\
COVID-19 (Y) & \\
\hline Worried about the personal problems & $($ Mean) \\
Personal physical health & 2.4 \\
Personal mental health & 2.4 \\
Studying issues & 2.8 \\
Future education & 3.3 \\
Family and relationship & 2.8 \\
Professional career in the future & 3.3 \\
Similar pandemic crisis in the future & 2.6 \\
Leisure activities & 2.6 \\
\hline &
\end{tabular}

\section{RECOMMENDATIONS :}

The unprecedented situation of the COVID-19 pandemic has compelled educational institutions to go for a completely online mode. The sudden shift from the conventional mode of learning to the complete online mode has a tremendous impact on the overall well-being of students. Since learning in online mode is the only possibility to continue education without wasting a year or two, one cannot avoid it. However, some 
recommendations can be made for the successful implementation of online learning. If students try to follow them the health hazards can be reduced.

- Virtual learning should be limited to 3-4 hours per day since extensive use of technology, as well as time spent in front of screens and using devices, has been related to physical, mental, and emotional health challenges.

- Because online learning is more flexible, most students do not strictly adhere to timetables. Unscheduled activities put an extra burden on the body and disrupt sleep patterns. Using one's bedroom as a virtual classroom might also create a stressful environment. Using the bedroom to attend online classes should be avoided. To put it another way, learning should not be brought to bed.

- Students become overburdened as a result of rigorous academic tasks online and offline. Time management is critical for reducing the stress and anxiety generated by online learning. Distress is greatly influenced by time management. Stress can be reduced if available time is used wisely. The learning environment must be kept clean and orderly. Folders should be used to organize digital learning materials. Participating in stress-relieving activities can also improve mood and create a healthy learning environment. Students should take a short break while online studying because it is an excellent technique to adjust one's mood.

- Students will be unable to retain information if learning is not methodical. They will be able to hold the information for a longer period if they use a scientific approach to learning and choose the ideal type of content for them depending on their cognitive abilities. Involving in mentally stimulating activities such as solving puzzles will sharpen the memory.

- Setting up a comfortable and well-ventilated place for study, keeping the cellphone in do-not-disturb mode to avoid endless notifications from several apps, avoiding the use of social media, keeping the body well hydrated, getting a good night's sleep, and following a healthy diet can enhance the concentration of students during online classes

- Interacting with friends and family members, being involved in hobbies, etc. can reduce social isolation. It is disheartening that many students consider online activities such as computer games, watching web series, involving in social media activities, etc. as their stress-busters. This in turn increases social isolation. Hence it is high time for them to go for 'internet fasting'. During online learning when 'internet fasting' is not possible, they can at least practice 'internet diet' to reduce online activities other than learning.

- Having positive feelings towards online learning, feeling optimistic that the current situation will be better shortly can reduce extreme fear and anxiety

- Following a healthy diet, involving in physical activities regularly can instill a positive attitude among students. If they are confident to face the challenges of online learning there will not be any negative thoughts such as depression, suicidal syndrome, and addiction.

- Sedentary nature of online learning activities, consumption of high-calorie food body weight. Following a balanced diet, regular sleep patterns, and involving actively in physical activities can help students gain excess body weight.

- Use of ergonomic furniture, sitting in proper posture, taking short breaks, following quick upper body stretching for a short period of 2 seconds can reduce strain, back pain, and fatigue. It is recommended to follow some quick relaxation techniques to overcome pains in the body because of online learning

- Self-care, self-confidence, and self-motivation are very much essential to stay fit and healthy during online learning. As good sleep is very much essential, it is essential to practice healthy bedroom habits. Laptops and smartphones are to be closed at least an hour before the bedtime

- The furniture and gadgets are to be adjusted properly to ensure minimum discomfort. Sitting in a 90degree posture with proper support at back can reduce strain

\section{CONCLUSION :}

COVID-19 has had a significant impact on our lives. Students, unfortunately, are among those who may be most affected by the virus. Whether it is mental health, physical health, or a mixture of the two, students have experienced their fair share of health issues during this pandemic. Students who take online lessons from home do not have to be as professional as their peers in the classroom. As a result, several areas of their 
physical health are worsening. One of the most prominent explanations for the current upsurge in backaches is poor ergonomics, such as attending online classes on beds and sofas. Obesity is on the rise in youngsters, either as a result of a lack of outdoor physical activity or as a result of binge eating and easy access to junk food at home. Youngsters are also losing muscle mass and gaining fat, which will hinder their growth. The fact is that the more physically active a youngster is during his or her growing years, the better their physical and mental health will be for the next three to four decades. Due to the current health crisis, this is completely absent. A lack of physical exercise, lack of adequate exposure to sunlight, and an imbalanced diet are all factors that contribute to calcium and vitamin D deficiencies. Muscle cramps, twinges, and strains/tears are typical in children with severe impairments owing to minor traumas or bad posture. Moreover, students are finding it difficult to cope with remote education options which is indirectly increasing stress on them. Every youngster wishes to be outdoor, and their fitness has deteriorated as a result of the confinement. Students who were isolated at home struggled with depression. In this study, the researchers shed light on the health difficulties that students are experiencing as a result of their engagement in technology-assisted online education. There have also been some suggestions for the use of educators and students so that students can maintain their health without disturbance. Researchers hope that the information interpreted and analyzed in the study will also help managers to simplify online methods and techniques of delivery of education.

\section{REFERENCES :}

[1] Aristovnik, A., Keržič, D., Ravšelj, D., Tomaževič, N., \& Umek, L. (2020). Impacts of the COVID-19 pandemic on the life of higher education students: A global perspective. Sustainability, 12(20), 1-34.

[2] Krishna Prasad, K., Aithal, P. S., Geetha Poornima, K., \& Vinayachandra, (2021). An AI-based Analysis of the effect of COVID-19 Stringency Index on Infection rates: A case of India. International Journal of Health Sciences and Pharmacy (IJHSP), 5(1), 87-102.

[3] Krishna Prasad, K., \& Vinayachandra, G. P. K. \& Rajeshwari, M. (2020). Effect of COVID-19 on Technology Penetration: a Predictive Analysis. Alochana Chakra Journal, 9(5), 2949-2967.

[4] Geetha Poornima K, Rajeshwari M, Vinayachandra, \& Krishna Prasad K. (2020). Web-Oriented Things Systems with 5T Policy to Manage and Contain COVID-19. International Journal of Applied Engineering and Management Letters (IJAEML), 4(2), 138-158.

[5] Vinayachandra, Geetha Poornima K., Rajeshwari, M. \& Krishna Prasad, K. (2021). Students' Perception of the Effectiveness of Technology-Assisted Online Education DuringCOVID-19 Pandemic: An Empirical Study. International Journal of Management, Technology, and Social Sciences (IJMTS), 6(1), 203-225.

[6] Vinayachandra, Geetha Poornima K., Rajeshwari M., \& Krishna Prasad K. (2021). Students' Perception of the Effectiveness of Technology-Assisted Online Education During COVID-19 Pandemic: An Empirical Study. International Journal of Management, Technology and Social Sciences (IJMTS), 6(1), 203-225.

[7] Radu, M. C., Schnakovszky, C., Herghelegiu, E., Ciubotariu, V. A., \& Cristea, I. (2020). The impact of the COVID-19 pandemic on the quality of educational process: A student survey. International Journal of Environmental Research and Public Health, 17(21), 1-15.

[8] Geetha Poornima K., Vinayachandra, Rajeshwari M., \& Krishna Prasad K. (2021). The Effect of Integration of Different Online Education Methods on Educational Advancement and Student Development: A Study. International Journal of Case Studies in Business, IT and Education (IJCSBE), 5(1), 200-220.

[9] Geetha Poornima, K., Rajeshwari, M., Vinayachandra, \& Krishna Prasad, K. (2020). Integration of Adaptive Technologies with Healthcare for the Early Identification and Control of COVID-19 Pandemic Disease. International Journal of Health Sciences and Pharmacy (IJHSP), 4(2), 5-28.

[10] Rajeshwari, M., Vinayachandra, K., Geetha Poornima, \& Krishna Prasad, K. (2021). An Analysis into the Contribution of Google Applications in the Successful Implementation of Online Education During the COVID-19 Pandemic. International Journal of Applied Engineering and Management Letters (IJAEML), 5(1), 131-152. 
[11] Händel, M., Stephan, M., Gläser-Zikuda, M., Kopp, B., Bedenlier, S., \& Ziegler, A. (2020). Digital readiness and its effects on higher education students' socio-emotional perceptions in the context of the COVID-19 pandemic. Journal of Research on Technology in Education, 1(1), 1-13.

[12] Chaturvedi, K., Vishwakarma, D. K., \& Singh, N. (2021). COVID-19 and its impact on education, social life and mental health of students: A survey. Children and Youth Services Review, 121(7), 1-6.

[13] Dangal, M. R., \&Maharjan, R. (2021). Health Problems Experienced in Online Learning During COVID-19 in Nepali Universities. International Journal of Online Graduate Education, 4(1), 1-14.

[14] Halupa, C. (2016). Risks: the impact of online learning and technology on student physical, mental, emotional, and social health. In International Technology, Education and Development Conference, 110.

[15] Choi, B., Jegatheeswaran, L., Minocha, A., Alhilani, M., Nakhoul, M., \& Mutengesa, E. (2020). The impact of the COVID-19 pandemic on final year medical students in the United Kingdom: a national survey. BMC medical education, 20(1), 1-11.

[16] Celik, B., \& Dane, S. (2020). The effects of COVID-19 Pandemic Outbreak on Food Consumption Preferences and Their Causes. Journal of Research in Medical and Dental Science, 8(3), 169-173.

[17] Zhang, Y., Zhang, H., Ma, X., \& Di, Q. (2020). Mental health problems during the COVID-19 pandemics and the mitigation effects of exercise: A longitudinal study of college students in China. International Journal of Environmental Research and Public Health, 17(10), 1-16.

[18] Zhao, Y., Guo, Y., Xiao, Y., Zhu, R., Sun, W., Huang, W., \& Wu, J. L. (2020). The effects of online homeschooling on children, parents, and teachers of grades 1-9 during the COVID-19 pandemic. Medical Science Monitor: International Medical Journal of Experimental and Clinical Research, 26(1), e925591.

[19] Hamza, C. A., Ewing, L., Heath, N. L., \& Goldstein, A. L. (2021). When social isolation is nothing new: A longitudinal study on psychological distress during COVID-19 among university students with and without preexisting mental health concerns. Canadian Psychology, 62(1), 20-30.

[20] Ammar, A., Brach, M., Trabelsi, K., Chtourou, H., Boukhris, O., Masmoudi, L., Bouaziz, B., Bentlage, E., How, D., Ahmed, M., Müller, P., Müller, N., Aloui, A., \& Hammouda, O. (2020). Effects of COVID-19 Home Confinement on Eating Behaviour and Physical Activity: Results of the ECLBCOVID19 International Online Survey, Nutrients, 12(6), 13-27

[21] Froman, V., Berumen D., Rodriguez Jaime., Stute Cathy (2020). COVID-19 Student Survey : Online Learning Experiences and Challenges Experienced Related to the COVID-19 Pandemic. Mt. SAC COVID-19 Student Survey, 1(1), 1-44.

[22] Akdeniz, G., Kavakci, M., Gozugok, M., Yalcinkaya, S., Kucukay, A., \&Sahutogullari, B. (2020). A Survey of Attitudes, Anxiety Status, and Protective Behaviors of the University Students During the COVID-19 Outbreak in Turkey. Frontiers in Psychiatry, 11(7), 1-9.

[23] Unger, S., \&Meiran, W. R. (2020). Student attitudes towards online education during the COVID-19 viral outbreak of 2020: Distance learning in a time of social distance. International Journal of Technology in Education and Science (IJTES), 4(4), 256-266.

[24] Alenezi, A. M. (2020). The relationship of students' emotional intelligence and the level of their readiness for online education: A contextual study on the example of university training in Saudi Arabia. Obrazovaniei Nauka, 22(4), 89-109.

[25] Chandra, Y. (2021). Online education during COVID-19: perception of academic stress and emotional intelligence coping strategies among college students. Asian Education and Development Studies, 10(2), 229-238.

[26] Yadav, A. K. (2020). Impact of Online Teaching on Students' Education and Health in India during the Pandemic of COVID-19. Coronaviruses, 2(4), 516-520. 
[27] Hasan, N., \& Bao, Y. (2020). Impact of" e-Learning crack-up" perception on psychological distress among college students during COVID-19 pandemic: A mediating role of" fear of academic year loss". Children and Youth Services Review, 118(1), 1-10.

[28] Chakraborty, P., Mittal, P., Gupta, M. S., Yadav, S., \& Arora, A. (2021). Opinion of students on online education during the COVID -19 pandemic. Human Behav and Emerg Tech, 3(3), 357-365.

[29] Son, C., Hegde, S., Smith, A., Wang, X., \&Sasangohar, F. (2020). Effects of COVID-19 on college students' mental health in the United States: Interview survey study. Journal of Medical Internet Research, 22(9), 1-14.

[30] Kecojevic, A., Basch, C. H., Sullivan, M., \&Davi, N. K. (2020). The impact of the COVID-19 epidemic on mental health of undergraduate students in New Jersey, cross-sectional study. PLoS ONE, 15(11), $1-16$.

[31] Muscogiuri, G., Pugliese, G., Barrea, L., Savastano, S., \& Colao, A. (2020). Commentary: obesity: the "Achilles heel" for COVID-19?. Metabolism-Clinical and Experimental, 108(1), 1-3.

[32] Wang, C., Pan, R., Wan, X., Tan, Y., Xu, L., Ho, C. S., \& Ho, R. C. (2020). Immediate psychological responses and associated factors during the initial stage of the 2019 coronavirus disease (COVID-19) epidemic among the general population in China. International journal of environmental research and public health, 17(5), 1-25.

[33] Van Strien, T. (2018). Causes of emotional eating and matched treatment of obesity. Current diabetes reports, 18(6), 1-8.

[34] Velavan, T. P., \& Meyer, C. G. (2020). The COVID-19 epidemic. Tropical medicine \& international health, 25(3), 278-280.

[35] Muscogiuri, G., Barrea, L., Annunziata, G., Di Somma, C., Laudisio, D., Colao, A., \&Savastano, S. (2019). Obesity and sleep disturbance: the chicken or the egg?.Critical reviews in food science and nutrition, 59(13), 2158-2165.

[36] Pugliese, G., Barrea, L., Laudisio, D., Salzano, C., Aprano, S., Colao, A., ... \&Muscogiuri, G. (2020). Sleep apnea, obesity, and disturbed glucose homeostasis: epidemiologic evidence, biologic insights, and therapeutic strategies. Current obesity reports, 9(1), 30-38.

[37] Muscogiuri, G., Barrea, L., Aprano, S., Framondi, L., Di Matteo, R., Laudisio, D., ... \& Colao, A. (2020). Sleep quality in obesity: does adherence to the mediterranean diet matter?.Nutrients, 12(5), 111.

[38] Evers, C., Dingemans, A., Junghans, A. F., \& Boevé, A. (2018). Feeling bad or feeling good, does emotion affect your consumption of food? A meta-analysis of the experimental evidence. Neuroscience \& Biobehavioral Reviews, 92(1), 195-208.

[39] Singh, M. (2014). Mood, food, and obesity. Front Psychol. 5(1), 1-10.

[40] Panahi, S., \& Tremblay, A. (2018). Sedentariness and health: is sedentary behavior more than just physical inactivity?.Frontiers in public health, $6(1), 1-8$.

[41] Abenavoli, L., Cinaglia, P., Luzza, F., Gentile, I., \& Boccuto, L. (2020). Epidemiology of coronavirus disease outbreak: the Italian trends. Rev Recent Clin Trials, 15(2), 87-92.

[42] Wang, C., Horby, P. W., Hayden, F. G., \& Gao, G. F. (2020). A novel coronavirus outbreak of global health concern. The lancet, 395(10223), 470-473.

[43] Moynihan, A. B., Van Tilburg, W. A., Igou, E. R., Wisman, A., Donnelly, A. E., \& Mulcaire, J. B. (2015). Eaten up by boredom: consuming food to escape awareness of the bored self. Frontiers in psychology, 6(1), 1-10.

[44] Jayawardena, R., Sooriyaarachchi, P., Chourdakis, M., Jeewandara, C., \& Ranasinghe, P. (2020). Enhancing immunity in viral infections, with special emphasis on COVID-19: A review. Diabetes \& Metabolic Syndrome: Clinical Research \& Reviews, 14(4), 367-382. 
[45] Wu, C., Chen, X., Cai, Y., Zhou, X., Xu, S., Huang, H., ... \& Song, Y. (2020). Risk factors associated with acute respiratory distress syndrome and death in patients with coronavirus disease 2019 pneumonia in Wuhan, China. JAMA internal medicine, 180(7), 934-943.

[46] Dhurandhar, N. V., Bailey, D., \& Thomas, D. (2015). Interaction of obesity and infections. Obesity Reviews, 16(12), 1017-1029.

[47] Dietz, W., \& Santos-Burgoa, C. (2020). Obesity and its implications for COVID-19 mortality. Obesity (Silver Spring), 28(6), 1-2.

[48] De Lorenzo, A., Romano, L., Di Renzo, L., Di Lorenzo, N., Cenname, G., \& Gualtieri, P. (2020). Obesity: a preventable, treatable, but relapsing disease. Nutrition, 71(1), 1-8.

[49] Di Renzo, L., Gualtieri, P., Romano, L., Marrone, G., Noce, A., Pujia, A., ... \& De Lorenzo, A. (2019). Role of personalized nutrition in chronic-degenerative diseases. Nutrients, 11(8), 1-24.

[50] Schröder, H., Fitó, M., Estruch, R., Martínez-González, M. A., Corella, D., Salas-Salvadó, J., ... \& Covas, M. I. (2011). A short screener is valid for assessing Mediterranean diet adherence among older Spanish men and women. The Journal of nutrition, 141(6), 1140-1145.

[51] Rodríguez-Martín, B. C., \& Meule, A. (2015). Food craving: new contributions on its assessment, moderators, and consequences. Frontiers in psychology, 6(1), 1-3.

[52] de Miranda, R. C., Di Renzo, L., Cupertino, V., Romano, L., De Lorenzo, A., Salimei, C., \& De Lorenzo, A. (2019). Secular trend of childhood nutritional status in Calabria (Italy) and the United States: the spread of obesity. Nutrition Research, 62(1), 23-31.

[53] De Lorenzo, A., Gratteri, S., Gualtieri, P., Cammarano, A., Bertucci, P., \& Di Renzo, L. (2019). Why primary obesity is a disease?.Journal of translational medicine, 17(1), 1-13.

[54] Cani, P. D., \& Van Hul, M. (2020). Mediterranean diet, gut microbiota and health: when age and calories do not add up!.Gut, 69(7), 1167-1168.

[55] García, O. P., Long, K. Z., \& Rosado, J. L. (2009). Impact of micronutrient deficiencies on obesity. Nutrition reviews, 67(10), 559-572.

[56] Ma, Y., Ratnasabapathy, R., \& Gardiner, J. (2017). Carbohydrate Craving-not everything is sweet. Current opinion in clinical nutrition and metabolic care, 20(4), 1-8.

[57] Y1lmaz, C., \&Gökmen, V. (2020). Neuroactive compounds in foods: Occurrence, mechanism and potential health effects. Food Research International, 128(1), 1-2.

[58] De Lorenzo, A., Bernardini, S., Gualtieri, P., Cabibbo, A., Perrone, M. A., Giambini, I., \& Di Renzo, L. (2017). Mediterranean meal versus Western meal effects on postprandial ox-LDL, oxidative and inflammatory gene expression in healthy subjects: a randomized controlled trial for nutrigenomic approach in cardiometabolic risk. Acta diabetologica, 54(2), 141-149.

[59] Engin, A. B., Engin, E. D., \& Engin, A. (2020). Two important controversial risk factors in SARSCoV-2 infection: obesity and smoking. Environmental toxicology and pharmacology, 78(1), 1-8.

[60] Soldati, L., Di Renzo, L., Jirillo, E., Ascierto, P. A., Marincola, F. M., \& De Lorenzo, A. (2018). The influence of diet on anti-cancer immune responsiveness. Journal of translational medicine, 16(1), 118.

[61] Nappi, F., Barrea, L., Di Somma, C., Savanelli, M. C., Muscogiuri, G., Orio, F., \& Savastano, S. (2016). Endocrine aspects of environmental "obesogen" pollutants. International journal of environmental research and public health, 13(8), 1-16. 